\title{
Do Childhood Experiences of Parental Separation Lead to Homelessness?
}

\author{
Julie Moschion (Corresponding author) \\ Melbourne Institute of Applied Economic and Social Research, University of Melbourne; \\ ARC Centre of Excellence for Children and \\ Families over the Life Course; IZA (Bonn); moschion@unimelb.edu.au. \\ Jan C. van Ours \\ Erasmus School of Economics, Erasmus University Rotterdam and Tinbergen Institute \\ (Amsterdam/Rotterdam); Department of Economics, University of Melbourne; CEPR \\ (London); IZA (Bonn); vanours@ese.eur.nl.
}

4 October 2018

\begin{abstract}
This paper investigates whether parental separation increases the likelihood of becoming homeless for disadvantaged households. Previous studies have only provided descriptive evidence for the general population suggesting that parental separations relate to reductions in housing quality and stability. Using a unique dataset of disadvantaged Australians who provide retrospective information on parental separation and housing circumstances, we examine transitions into homelessness following parental separation. Accounting for observed as well as unobserved family and individual characteristics, and exploiting the timing of events, we show that parental separation significantly increases the likelihood of experiencing homelessness among children under the age of 12 . For older children, parental separation increases the likelihood of boys becoming homeless, but not girls.
\end{abstract}

Keywords: Parental separation, Homelessness, Australia

JEL-codes: D12, J12

\footnotetext{
*Acknowledgements: This paper uses unit record data from Journeys Home: Longitudinal Study of Factors Affecting Housing Stability (Journeys Home). The study was initiated and is funded by the Australian Government Department of Social Services (DSS) and was approved by the Human Research Ethics Committee of the University of Melbourne. The Department of Employment has provided information for use in Journeys Home and it is managed by the Melbourne Institute of Applied Economic and Social Research (Melbourne Institute). The findings and views reported in this paper, however, are those of the authors and should not be attributed to DSS, the Department of Employment or the Melbourne Institute. The authors would like to thank Melisa Bubonya, William N. Evans, Dan O'Flaherty, Leslie Martin, Nicolas Salamanca, Kjell Salvanes, Yi-Ping Tseng and participants at the Columbia Population Research Center Seminar (Columbia School of Social Work) and at the Urban Seminar of the Furman Center (New York University) for useful comments on earlier drafts.
} 


\section{Introduction}

Most parental separations do not lead children to homelessness, but for disadvantaged households, parental separation could make all the difference. There are many reasons why parental separation could trigger homelessness among vulnerable populations. Parental separation, which implies a duplication of household expenses, can generate a large shock to household finances. While most households have the financial and social resources to cope with the monetary consequences of a separation, this shock may be what makes disadvantaged families tip over into homelessness. Indeed, O'Flaherty $(2004,2009 \& 2010)$ proposes a theory and presents descriptive evidence of why and how shocks (i.e. unexpected changes in circumstances such as a negative income shock) can precipitate homelessness, especially among disadvantaged groups. Such deterioration of households' financial resources could also lead to homelessness even years after the separation occurred as less disadvantaged groups may be able to cope financially in the short run (by covering housing costs with their savings for example), but not in the medium run (once those savings have run out). In addition, parental separations can also create conflict between parents and children, to the point of driving children out of their parent's home and potentially into homelessness in subsequent years.

This paper investigates the effect of parental separation on family and youth homelessness among disadvantaged households using Journeys Home (JH), a unique dataset of Australian income support recipients who are homeless or at-risk of homelessness. We use the retrospective information provided by respondents about their childhood experiences of parental separation and homelessness to estimate the immediate and delayed effect of parental separation on homelessness. In the JH sample, family breakdown appears to be an important trigger for children's and young adults' homelessness. For instance, of those who have experienced homelessness before age 30, 68 percent were the children of separated parents. In contrast, vulnerable individuals that did not experience homelessness before age 30 were only 
half as likely to have had separated parents. Furthermore, 62 percent of respondents specifically identify family breakdown or conflict as the main reason for becoming homeless for the first time (Scutella et al., 2012). ${ }^{1}$ Again, this is more prevalent among respondents who have experienced homelessness before $30(68 \%)$ than among those who became homeless later in life $(45 \%)$.

Although only a minority of the population will face homelessness in their lifetime, for those who do it is one of the most difficult hardships they will ever endure. Homelessness is associated with significant financial and social deprivations, mental and physical health issues and socially undesirable behaviours such as substance abuse and crime (Philippot et al., 2007). For those experiencing homelessness at an early age, the consequences may be even more devastating, with long lasting effects on educational and health outcomes, employment and earnings potential, social integration, and financial autonomy. Understanding how individuals, in particular children or young adults, become homeless is an important first step towards developing policies that may prevent homelessness and curb the wide range of difficulties associated with homelessness, especially for those from disadvantaged backgrounds. Yet, the relationship between parental separation and homelessness is difficult to identify because data on vulnerable individuals over long periods of time is rarely available.

Our contribution to the literature is threefold. First, we present original evidence which is based on a large-scale, broad-based survey of disadvantaged individuals who are homeless or at risk of homelessness. Investigating the relationship between parental separation and homelessness is difficult because most datasets available are not well suited to this purpose. Disadvantaged populations (i.e. that have experienced homelessness) are underrepresented in

\footnotetext{
${ }^{1}$ This is a large majority given that the next most cited answer "Domestic and family violence or abuse" gathers only $18 \%$ of answers. Note that "family breakdown or conflict" is broader than "parental separation" given that it might include conflicts without any separation as well as the respondent's own separation from her or his partner.
} 
general household surveys; and datasets which only include people who are currently homeless fail to capture other segments of the disadvantaged population who might be at risk of homelessness. In contrast, JH is unique in that it covers a broad spectrum of the disadvantaged population, not just those currently homeless. In fact, 75 percent of respondents were not homeless at the time of the first interview (Scutella et al., 2012). ${ }^{2}$ At the same time, the high frequency of homelessness and parental separation in the sample provides sufficient variation in the timing of events to address the question of a potential causal relationship between the two. Importantly, JH has detailed information on respondents' histories, including information about their age when they were homeless for the first time (if ever), and their age when their parents separated (if ever).

Second, we go further than previous studies in exploring the degree to which the association between parental separation and homelessness might be plausibly interpreted as a causal relationship. Cross-sectional analyses of the determinants of homelessness are subject to reverse causality or omitted variable bias. For example, in our case, parental separation and homelessness may be independently determined by family violence or parents' substance use for example. We take advantage of our uniquely rich dataset to control for a wide range of childhood adverse experiences (e.g. emotional abuse, physical and sexual violence). We then implement bivariate mixed proportional hazard models to deal with reverse causality and omitted variable bias arising from unobserved time-invariant characteristics. In these models, parental separation and the transitions into homelessness form a fully simultaneous system. This estimation strategy deals with omitted variable bias by allowing the unobserved heterogeneity terms affecting each transition rate to be potentially correlated. We then exploit

\footnotetext{
${ }^{2}$ Essentially, the JH sample represents Australians who are in the bottom percentile of the socio-economic ladder, accumulating disadvantages along all standard economic and social dimensions (education, employment, income, health, housing etc. - see section 3.1 for more details).
} 
the timing of first episodes to identify the direction of causality linking parental separation to homelessness. Time-varying unobservable shocks remain a threat to our identification strategy but although we cannot identify pure causal effects, we make a significant step in that direction.

Finally, we distinguish between the effect of parental separation for young children (below 12 years old) and for teenagers and young adults (12 to 30 years old). The timing of the parental separation may indeed matter in that it may lead to distinctive types of homelessness, with different consequences: family homelessness and youth homelessness (Toro \& al., 2007; Rog \& Buckner, 2007). In this context, the likelihood that parental separation leads to homelessness could vary with the age of the children. On the one hand, younger children have (on average) younger parents with less financial resources to deal with a separation thereby increasing the risk of homelessness for the family. On the other hand, as the children become teenagers and young adults, the risk of them becoming homeless increases, potentially because of parental separation and associated conflicts. Overall, whether the consequences of parental separation on homelessness should increase or decrease with the age of the child is an unanswered but relevant empirical question.

We find a substantial effect of parental separation on the entry into homelessness. Conditional on family and individual characteristics, if parents separate before the child reaches age 12 , boys (resp. girls) have a 10-15 (resp. 15-20) percentage points greater chance of becoming homeless by age 30 . However, if the parental separation occurs from age 12 onwards the effect only persists for boys, who are at greater risk of becoming homeless. This is in line with the recent literature finding that boys are particularly affected by growing up in a broken family (Bertrand \& Pan, 2013).

Following the previous housing literature, we then investigate whether the effect of parental separation differs between parents that were formally married and those that were in a de facto relationship. We find larger effects on homelessness when the parents were formally 
married prior to the separation. Lastly, broader or stricter definitions of homelessness have been used in the literature. We therefore estimate the effect of parental separation differentiating between respondents who experienced literal homelessness and respondents who experience homelessness more broadly defined. Our main findings are insensitive to the definition of homelessness.

The remainder of our paper is structured as follows. In section 2 we review the relevant literature and in Section 3 we present our data and the results from a descriptive analysis. Section 4 describes the set-up of our empirical analysis. In section 5 we present and discuss our baseline parameter estimates. We explore the robustness of our main findings by presenting a range of sensitivity analyses in Section 6, while Section 7 concludes.

\section{Literature review}

Empirical evidence on the relationship between childhood experiences of parental separation and homelessness consistently points to family breakdown as a potentially major contributor to homelessness. However, previous studies are essentially descriptive in nature. Shinn et al. (2007) points to divorce and separations as frequently cited contributors to homelessness, together with financial difficulties, domestic violence, mental health problems, substance abuse and incarceration (Firdion \& Marpsat, 2007; Hladikova \& Hradecky, 2007; Okamoto, 2007; Philippot et al., 2007). Others frequently report that most homeless children and youth come from single-parent or blended households (Toro et al. 2007; Rog \& Buckner, 2007). Unfortunately, these studies only suggest a conjunction of factors that lead people to have separated parents and lose their home. It is therefore unclear whether parental separation alone contributes to the onset of homelessness of children and young adults. 
A small housing literature has paid some attention to the housing outcomes of families that experience divorce and/or separations, but the focus is on the broader population rather than a disadvantaged population who are at-risk of homelessness. There is indeed some evidence that parental separation is associated with a downward trend in housing quality since a separation often implies an urgent move and a decrease in resources. Specifically, a separation frequently leads the separating couple to move out of home ownership; to move out of singlefamily housing; to sometimes move back into their parents' home or into some form of shared accommodation. Overall, separations decrease the quality of housing and increase housing instability (Flatau et al., 2004; Feijten, 2005; Dewilde, 2008; Feijten \& van Ham, 2010).

The findings that parental separation is related to housing difficulties are likely to be spurious, however, if researchers do not account for the fact that family structure is probably correlated with other determinants of a family's housing situation. Indeed, there are good reasons why parental separation may not be a random event. The factors that caused the separation may also affect the families' housing situation through other pathways, such as a parent's addiction to drugs or financial difficulties. Further, the impact of homelessness on parental separation, although less obvious, should also not be ruled out a priori: the stress resulting from being homeless could increase the risk of a separation. ${ }^{3}$ As such, the existing literature is largely correlational and may yield misleading results, due to the potential for omitted variables and reverse causality. We are unaware of any studies attempting to identify the causal impact of parental separation on children's homelessness.

An emerging literature attempts to identify whether other characteristics commonly associated with homelessness could indeed cause homelessness, i.e. whether the associations found in the descriptive data hold true once applying more rigorous econometric methods. The answer is mostly no, highlighting the importance of using an identification strategy that deals

\footnotetext{
${ }^{3}$ Boyle et al. (2008) actually find a higher risk of separation after moving twice or more.
} 
with potential biases. For example, using individual fixed effects, McVicar et al. (2015) find that the use of most substances (cannabis and street drugs) do not increase transitions into homelessness 6 months later, except for alcohol abuse. Using a similar methodology to the current paper to investigate the impact of beginning to use cannabis daily and street drugs weekly on the onset of homelessness, McVicar et al. (2017) find that substance use mostly does not lead to homelessness (except for boys' daily use of cannabis).

On the other side of the spectrum, the divorce literature is mainly focused on the consequences of parental separation on children's outcomes, rather than on housing outcomes (see McLanahan et al., 2013 for a review). Economists interested in identifying a causal impact of parental separation have also emphasized the need to address endogeneity issues. Typically, this has involved exploiting plausibly exogenous sources of variation in family structure through natural experiments or instrumental variables methods (Lang \& Zagorsky, 2001; Gruber, 2004; Finlay \& Neumark, 2010) and accounting for unobserved heterogeneity through the use of individual fixed effects (Cherlin et al., 1991), sibling fixed effects (Ermisch et al., 2004; Evenhouse \& Reilly, 2004) and propensity score matching (Gertler et al., 2004). After accounting for endogeneity issues, these studies tend to find that divorce does not deteriorate children's outcomes. Only rarely do researchers interested in family and household issues explicitly address the connections between housing on the one hand, and household formation or dissolution on the other (Mulder \& Lauster, 2010).

Overall, whether parental separation increases housing difficulties is unclear and whether it increases homelessness is even more obscure. Yet, establishing the extent to which associations between parental separation and homelessness are simply correlations or are reflecting a causal relationship is crucial for the development of sound policies to prevent homelessness. A positive causal effect from parental separation to homelessness suggests that 
interventions designed to support disadvantaged families in which parents separate may effectively reduce inflows into homelessness.

The objective of this paper is to make some progress in that direction and estimate the immediate and delayed effect of parental separation on homelessness for a population of disadvantaged Australians, separately by gender and by the age of the child at the age of separation.

\section{Data and descriptive analysis}

\subsection{The JH data and variable definitions}

$\mathrm{JH}$ is a longitudinal dataset with information on a sample of income support recipients (i.e. welfare recipients) who are either homeless or at-risk of homelessness. Previous studies of homelessness have focused on specific homeless groups, such as those sleeping rough or those staying in emergency accommodation at a certain point in time and often in a particular geographic area (e.g. Corno, 2017). In comparison, the JH sample was drawn from a broader population of disadvantaged Australians, who are not necessarily homeless when joining the study, but are facing or have faced some form of housing instability in their life. In fact, only 25 percent of $\mathrm{JH}$ respondents were homeless at the first interview. This gives us the opportunity

to study the processes leading to homelessness using a broader population of disadvantaged people who are at-risk of homelessness and housing instability. As much as it is important to study homelessness for a broad population, homelessness cannot be studied in data sources representative of the general population (e.g. Censuses, household panel datasets) because of its low prevalence. For instance, as of wave 1, 94 percent of $\mathrm{JH}$ respondents had been homeless at some point in their lives, compared with only 13 percent in the Australian population aged 15 years and over (Australian Bureau of Statistics, 2014). At the same time, selecting a sample 
of the population which is at-risk potentially generates biases due to selection on the outcome. Appendix 1 discusses this issue suggesting that our estimates are more likely to be biased downwards.

The JH sample was drawn from administrative data which covers all Australians aged 15 years or older in receipt of any income support payments at any time during the 28-day period prior to 27 May 2011. Interestingly, Australia has the specificity that all income support payments (e.g. family benefits, single-parent benefits, disability benefits, rent assistance...) are administered by the same government agency (Centrelink). This facilitates the identification of disadvantaged individuals facing housing insecurity issues as most of these individuals would be eligible for some form of social support. ${ }^{4}$

However, not all Australians receiving income support payments are homeless or atrisk of homelessness (more than $20 \%$ of the Australian population actually receives some form of government payment, some of which are independent of income like the childcare rebate for example). The JH population was therefore identified by exploiting: (i) flags that the Centrelink staff used from January 2010 to identify customers who are homeless or at-risk of homelessness; and (ii) statistical models to identify other customers who, although not flagged, were also vulnerable to homelessness. More precisely, local Centrelink's staff attributed flags following the definitions provided in Centrelink's Homelessness Awareness Training Manual. The Manual defines a homeless person as one that: "is without conventional accommodation (e.g., sleeping rough, squatting, or living in a car); or lives in, or moves frequently between, temporary accommodation arrangements (e.g., with friends or extended family, emergency

\footnotetext{
4 The administration of payments by a sole agency significantly simplifies application and payment procedures for homeless people and tracking processes for the administration. Therefore, we can expect a relatively small loss of our target population. In fact, around 85 percent of users of government-funded specialist homelessness programs relied on government payments as their main source of income in 2009/10 (Australian Institute of Health and Welfare 2011).
} 
accommodation, or youth refuges)"; and a person at-risk of homelessness as one that: "lives medium to long term in a boarding house, caravan park or hotel, where accommodation is not covered by a lease; lives in accommodation which falls below the general community standards which surround health and wellbeing, such as access to personal amenities, security against threat, privacy and autonomy; is facing eviction; or lives in accommodation not of an appropriate standard which may be detrimental to their physical and mental well-being, or where they have no sense of belonging or connection (e.g., Indigenous Australians living in crowded conditions or disconnected from their land, family / kin, spiritual and cultural beliefs and practices). Then a subpopulation of Centrelink customers that were identified as vulnerable to homelessness was added to the survey population. These individuals, although not flagged, had characteristics similar to flagged individuals. Probabilities of being flagged were estimated using logistic regressions that included a very large list of variables available in the administrative data, including key demographics, housing tenure type, residential mobility in the past year, earnings, income support history, medical conditions, incarceration history, substance use (see Table A1 in Melbourne Institute, 2012, for the full list). The vulnerable subpopulation was defined as individuals who had a relatively high probability of being flagged as homeless or at-risk of homelessness (i.e. with a probability in the top $2 \%$ among unflagged income support recipients).

Overall, a total survey population of 110,616 individuals was identified, from which a stratified random sample of 3,485 individuals across 36 distinct locations was activated. The random sample was greatly above the target sample of 1,500 to account for individuals becoming out of scope between the sampling and wave 1 fieldwork and for non-response to the survey. Indeed, 766 individuals (22\%) were deemed to be out of scope before wave 1 for a variety of reasons, ${ }^{5}$ leaving an in-scope sample of 2,719 . Almost 62 percent of this in-scope

\footnotetext{
${ }^{5}$ Individuals were considered to be out-of-scope if they: moved out of survey areas prior to fieldwork; died; were in prison or in another institution (note that individuals stay in the sample if they enter a carceral or other institution after wave 1); were overseas; required an interpreter; specifically indicated to Centrelink that they were not willing to participate in research studies; were a young person still at home with their parents (due to concerns about the difficulties of
} 
sample $(\mathrm{N}=1,682)$ agreed to participate in wave 1 which was conducted between September and November 2011.6 Becoming out-of-scope and non-response may not be random posing potential problems for the interpretation of our results. The in-scope sample appears largely similar to the initial activated sample. The responding sample, however, differs from the inscope sample along a few characteristics, especially gender and having dependent children (but also being an ex-offender and the type of benefit received from Centrelink). Those differences are very similar to differences in response rates found in other general surveys. All wave 1 respondents were then approached to be reinterviewed a further five times at six-monthly intervals (See Wooden et al., 2012 and Melbourne Institute, 2012 for more details on the sample design and differences between the activated, in-scope and responding samples).

$\mathrm{JH}$ respondents are amongst the most disadvantaged 1 percent of Australians. ${ }^{7}$ Overall, not only do JH respondents face more housing difficulties than average Australians, but they fare worse along every standard economic dimension and this accumulation of disadvantage deteriorates their relative situation even further. For example, only $39 \%$ of respondents have graduated from high school compared to $71 \%$ of the Australian population and only $20 \%$ were employed at wave 1 compared to $63 \%$ of the Australian population. JH respondents are also more often from indigenous backgrounds ( $20 \%$ vs $3 \%)$, have more mental health conditions (e.g. 54\% have been diagnosed with depression vs 12\%) and substance abuse problems (e.g. 57\% drink alcohol at risky level vs 20\%) than the general population (See Scutella et al. 2012 for more details). In addition, $\mathrm{JH}$ respondents earned a median individual gross income of

obtaining parental consent for persons under the age of 18 years who were still living with their parents).

${ }^{6}$ Non-responses consisted of: 500 that could not be contacted, 369 refusals, 168 for whom contact was made but no interview resulted.

7 Indeed, JH respondents were sampled from a survey population of 110,616 very disadvantaged income support recipients (Melbourne Institute, 2012), which represented 0.6 percent of the Australian population aged 15 and above in 2011 (Australian Bureau of Statistics). 
$\$ 15,756$ per year at wave 1 (including wages in all jobs, government payments and other incomes), which is comparable to the income earned by Australians at the 28th percentile of the Australian income distribution. Comparing the distribution of income for the JH sample to the general Australian population highlights that JH respondents' incomes are concentrated on the lower part of the income distribution, while Australian incomes are more spread out, especially towards higher incomes (over AUD 35000 a year, see Appendix 2).

In our analysis, we use the sample of respondents who were interviewed in wave 1 (September 2011) when retrospective information on the age of onset of homelessness was collected and in wave 6 (May 2014) when retrospective information on the timing of parental separation was collected ${ }^{8}$. Despite the disadvantaged nature of the JH sample, both the response rate at wave $1(62 \%)$ and the retention rate in the sample at wave $6(84 \%$ of wave 1 respondents, i.e. $\mathrm{N}=1,406)$ were high. Some respondents may make mistakes in reporting retrospective information about their childhood. The psychology literature has established that recalls in adult life have acceptable validity if the event was "serious, readily operationalised" (Hardt \& Rutter, 2004); "unique, consequential, and unexpected" (Brewin et al., 1993), which is most likely the case of parental separation and homelessness. At the same time, the few studies that have studied the accuracy of recall of the timing and sequence of adverse childhood experiences find that they are not very accurate, but the extent of the inaccuracy is unclear (Hardt \& Rutter, 2004). In our case, what matters most is that respondents get the timing of events right: what happened first and with what delay. Given that parental separation and first experiences of homelessness are substantial events which happen on average 10 years apart in our sample (see Table 1), we do not expect respondents to make systematic mistakes in reporting the sequence

\footnotetext{
${ }^{8}$ Here we use the retrospective information to study first experiences of homelessness. JH has also been used to study transitions in and out of homelessness over the survey period (McVicar et al., 2015; Cobb-Clark et al., 2016).
} 
of these two events. Still, we test the robustness of our results to potential misreporting in section 6 .

We transfer information on parental separation from wave 6 to the situation in wave 1 and consider both parental separation and homelessness as of wave $1 .{ }^{9}$ Because the effect of parental separation on the children's housing situation is likely to be more relevant when children still live with their parents, we focus on those events if they happen at 30 years old at the latest. In other words, we censor the parental separation and the onset of homelessness if they occur after 30 . We investigate the sensitivity of our results to this censoring in the robustness section.

Parental separation can be defined in at least one of two ways: by focussing on marriages ending up in divorce only or by also considering de facto relationships ending up in separations. We define the age at parental separation by the age of the respondent when his parents (first) divorced or separated. ${ }^{10}$ To compare respondents whose parents separated at different ages with respondents whose parents did not separate, we drop 71 respondents whose parents were never married or never were in a de facto relationship.

Homelessness can be defined in different ways and with different thresholds. Australia traditionally adopted a broad characterisation of homelessness which seeks to identify situations in which families' housing conditions do not meet standard requirements to qualify as a 'home' (Johnson \& Chamberlain, 2008; the Australian Bureau of Statistics). In the US, most of the research on homelessness used to focus on the literally homeless. More recently, some US research also includes the precariously housed arguing that this potentially larger group may be encountering similar risks to the literally homeless (Toro et al., 2007). This broad definition is

\footnotetext{
${ }^{9}$ Only 3 respondents have parents separating for the first time between wave 1 and wave 6 .

${ }^{10}$ See Appendix 3 for more details on the exact sequence of questions.
} 
indeed the definition adopted by the U.S 2009 Homeless Emergency Assistance and Rapid Transition to Housing Act; and the definition used by Link et al. (1994) and Curtis et al. (2013).

Following this evolution, we adopt a broad definition and define homelessness as: sleeping rough or squatting in abandoned buildings; staying with relatives or friends temporarily with no alternative; staying in a caravan park, boarding house, hotel or crisis accommodation ${ }^{11}$. Using this definition, for each respondent we construct the age at which she became homeless for the first time. If the respondent has been homeless prior to JH (i.e. if she has "stayed in any [...] places because [she] did not have a place to live"), we use the retrospective information collected at wave 1 on "How old [she was] the first time that [she was] without a place to live". ${ }^{12}$ Because this definition of homelessness is quite broad we investigate the robustness of our findings to a stricter definition of homelessness which includes only respondents with an experience of staying in crisis accommodation, sleeping rough or squatting in abandoned buildings. Unfortunately, the age of onset for literal homelessness is not available. So in that case, we estimate the effect of parental separation on the age of onset of homelessness (broadly defined) for the subset of respondents who have experienced literal homelessness as of wave 1.

Finally, the literature distinguishes family homelessness and youth homelessness as those may have different causes and consequences (Toro et al., 2007; Rog \& Buckner, 2007). Depending on the age of the child and therefore her potential exposure to family versus youth homelessness, the effect of parental separation on homelessness is likely to differ. The age distinction between the two categories of homelessness is not clear-cut. However, national estimates from the US suggest that the prevalence of youth homelessness is low until 12 (Greene et al., 1997; Sedlack et al., 2002) and the literature on youth homelessness finds that

\footnotetext{
11 Note that this definition of the homelessness outcome variable differs from the sample selection criteria described page 9 .

12 See Appendix 3 for more details on the exact sequence of questions.
} 
most homeless youth are 13 or older (Toro et al., 2007). Twelve years old also marks the transitions from childhood to teenage years and from primary school to high school, which may be especially meaningful when studying the consequences of parental separation. We therefore estimate separately the effect of parental separation before and after age 12 . We test the sensitivity of our results to this cut-off point in the robustness section.

Our estimating sample consists of respondents whose parents were married or in a de facto relationship and provided complete information on parental separation and the onset of homelessness, which translates to 1,231 observations, i.e. 73 percent of the wave 1 sample. Attrition could be non-random and therefore bias our results. However, the experience of homelessness before wave 1 (i.e. our main outcome) is unrelated to being in our sample. ${ }^{13} \mathrm{We}$ are thus confident that our estimates are not driven by sample selection.

\subsection{Descriptive statistics}

Table 1 shows the prevalence of parental separation and homelessness up to age 30 in our sample. Around 74 percent of women and 72 percent of men had experienced homelessness at wave 1 of the survey. More than half of the respondents have separated parents. Interestingly, more women have experienced parental separation than men ( 65 percent vs 57 percent). This is consistent with US evidence that rates of divorce are higher in families with girls than in families with boys, although this relationship is not confirmed for Australia (Bedard \& Deschenes, 2005; Leigh, 2009). On average, if parental separation and homelessness both occur it is very likely that parental separation occurred first. Parental separation occurs on average at around age seven to eight while homelessness occurs at around age 17 to 18 .

${ }^{13}$ When regressing a dummy variable for being in our sample (equal to 1 for the 1,231 respondents in our sample, 0 for other wave 1 respondents) on the homelessness status as of wave 1, the coefficient for homelessness is insignificant with or without any controls (online Appendix 4). 
Table 1 around here

Journeys Home also provides information about the type of accommodation respondents have ever lived in before being surveyed in Journeys Home. Most respondents experienced precarious housing (73 percent of women and 70 percent of men), especially via staying with relatives or friends with no alternatives. Literal homelessness is also very common in our sample, in particular via experiences of sleeping rough (35 percent of women and 52 percent of men).

Figures 1 and 2 illustrate the cumulative probability distributions for parental separation and the onset of homelessness up to age 30 , separately for women and men. ${ }^{14}$ The top graphs show that parental separation mostly occurs before the child reaches age 20. More precisely, parental separation sometimes occurs early with more than five percent of parents separating in the year following the birth of the child. Parental separation then increases sharply with about 47 percent of women experiencing parental separation before age 12 and 65 percent by age 30 (respectively 40 and 57 percent for men). The middle graphs of Figures 1 and 2 show that the onset of homelessness usually occurs later in life. The rate of homelessness stays relatively low with less than five percent of respondents experiencing homelessness before age 12. It then increases steeply between ages 12 and 16 to reach around a third of the sample. After that, the rate of homelessness continues to increase gradually. Around 20 percent of the $\mathrm{JH}$ sample experience homelessness for the first time after 30. This suggests that there are probably two very different experiences of homelessness: (i) those that occur at relatively young ages and may be related to the separation; (ii) much later experiences which are unlikely to be related to parental separation. This descriptive evidence therefore reinforces our choice to focus on

\footnotetext{
${ }^{14}$ If individuals were older than 30 at the time of the survey, we censor events occurring after age 30. If individuals are less than 30 years old and parental separation or homelessness had not occurred, we consider the process of becoming homeless or facing parental separation to be right-censored at that age.
} 
homelessness up to age 30 . In addition, we will differentiate our results by the age of the child because the effect of parental separation on homelessness may have different consequences depending on whether the separation occurs in a household with young children versus teenagers and young adults.

For illustrative purposes, in the bottom graphs of Figures 1 and 2 we split up the sample in three groups: parental separation occurred before age 12, parental separation occurred at age 12 or later, no parental separation. Men whose parents separated before they were 12 became homeless earlier than those whose parents separated between 12 and 30. Those men with parental separation occurring between ages 12 and 30 became homeless earlier than those whose parents did not separate by the time they were 30 years old. For women, the likelihood of becoming homeless is also higher if the parental separation occurred before 12 . However, for women, parental separations occurring after 12 do not seem to be related to the onset of homelessness.

Figures 1 and 2 about here

Under the non-anticipation assumption, if there is a significant causal relationship from parental separation to homelessness, then parental separation should, on average, precede the onset of homelessness. Figure 3 investigates this issue, representing the distribution of the possible combinations of timing of events with respect to parental separation and the onset of homelessness. For instance, 49 percent of women and 42 percent of men experienced parental separation before becoming homeless, while both happen at the same age for one percent of men (two percent of women). In contrast, two percent of women became homeless before their parents separated (three percent of men). The likelihood that parental separation occurs first is therefore very high, but one cannot dismiss a priori the possibility that the relationship between parental separation and homelessness is driven by unobserved heterogeneity. In contrast, the low occurrence of parental separation after homelessness suggests that for individuals in our 
sample homelessness has hardly ever led to parental separation. From this, we conclude that reverse causality is not an issue. In our analysis, we focus on identifying the potential causal effect of childhood experiences of parental separation on homelessness. In addition, the figures show onsets of homelessness both immediately and several years after the separation suggesting that: (i) parental separation could have a delayed effect; (ii) other factors may contribute to the association between parental separation and homelessness.

Figure 3 about here

Table 2 provides summary information for our sample. The JH sample grew up in a relatively disadvantaged situation with many respondents having experienced violence during childhood: on average across the sample more than half suffered from emotional abuse (58 percent) and physical violence (56 percent of girls and 63 of boys); and a significant proportion of respondents suffered from sexual violence ( 37 percent of girls and 15 percent of boys). By the age of 14,14 percent were not living with their biological parents because these were deceased or because of a conflict. When disaggregating the sample by experiences of homelessness, the rates of 'not living with parents' and violence are much higher among respondents who experienced homelessness before 30 compared to those who did not. This emphasises the fact that respondents experiencing early homelessness, not only experience parental separation more often and earlier, but also have other disadvantages which are also likely to be driving parental separations. To estimate the effect of parental separation on homelessness, it will therefore be important to control for observable differences as well as unobserved differences likely to jointly determine homelessness and parental separation.

Differences in the respondents' male and female caregiver's education are less striking, although both men and women who experienced homelessness before age 30 less often had caregivers with post-secondary education (e.g. 11 percent of women who experienced homelessness by age 30 had a male caregiver with a Technical College or University diploma 
versus 18.4 percent for women who had not experienced homelessness). This background information is missing for a significant portion of our sample and this item non-response is unlikely to be random. For instance, respondents with homeless experiences more often have missing information on their male caregiver's education. We therefore construct dummy variables for missing information on subsets of control variables: reason for not living with parents at 14 , violence, male caregiver and female caregiver's education.

Table 2 about here

Tables 3 and 4 present linear probability estimates of the effect of parental separation before age 12 on the probability of homelessness occurring respectively by the ages of 15,20 , 25 and 30 years old for women and men separately. The outcome is a dummy equal to 1 if the respondent becomes homeless by age 15/20/25/30 and 0 otherwise. Similarly, the parental separation variable is a dummy equal to 1 if the parental separation occurs before 12 and 0 otherwise. In our sample, 44 percent of respondents have parents separating before the child reaches age $12 .{ }^{15}$ We control for all observable characteristics described in Table 2 (which will also be included in the bivariate duration model).

We find positive and significant effects of parental separation on homelessness. The linear probability estimates suggest that women whose parents separated before age 12 have higher probabilities of becoming homeless by age 15 (by 13 percentage-points), by age 20 (by $25 \mathrm{pp}$ ), by age 25 (by 25pp), and by age 30 (by 22pp). Results for men are essentially similar with effects increasing until their $20 \mathrm{~s}$ and then decreasing before age $30 .{ }^{16}$ The regression analysis confirms the descriptive evidence: childhood characteristics differ between

\footnotetext{
${ }^{15}$ Note that for this analysis (only) we remove from the sample respondents who became homeless before age 12 (45 observations) to ensure that parental separation occurred before homelessness. Note also that for every estimate we restrict the sample to respondents who are at least 15, 20, 25 or 30 years of age respectively. So, as the age cut-off increases, the sample reduces in size.

${ }_{16}$ Probit and logit estimates are consistent in sign and magnitude (results available upon request).
} 
respondents who experienced homelessness and those who didn't, while caregivers' education levels do not differ. For boys and girls, conflicts with parents and physical violence matter especially for experiences of homelessness before age 15 , while emotional abuse matters more for homelessness onsets after 15.

These results suggest that respondents who have experienced the separation of their parents by age 12 are more likely to be homeless by age 30 than respondents who did not experience parental separation, even after controlling for observable factors. However, these estimates do not take account potential unobserved heterogeneity and they deal with the timing of events in an ad hoc way by dropping respondents who were homeless before the parental separation occurred and by focusing only on parental separations which occurred before age 12. The bivariate duration modelling enables us to deal with these issues and improve upon the simple linear probability models.

Table 3 and 4 about here

\section{$4 \quad$ Identification strategy}

The aim of this paper is to investigate whether parental separation affects the onset of homelessness. To do so, we use a bivariate mixed proportional hazard framework in which the two hazards relate to the transition to parental separation and to the (first) transition into homelessness. The model uses information about the age of the respondent when her parents separated and her age when she first became homeless. Bivariate duration modelling is a common empirical approach in parts of the social policy literature, e.g. the literature evaluating the impact of benefit sanctions on welfare exit and job entry (see for example Abbring et al., 2005 and Van den Berg et al., 2004). The bivariate duration approach has also been used in several studies of drug use impacts, most commonly to investigate various impacts of cannabis use (see Van Ours \& Williams, 2015 for a review). 
To investigate whether parental separation increases the likelihood of homelessness, we account for the possibility that the correlation between parental separation and homelessness reflects unobserved confounding factors. This is achieved by modelling the two transitions as a fully simultaneous system in which the unobserved heterogeneity terms determining each transition rate are jointly distributed. Also, prior parental separation enters the hazard for transitions into homelessness.

A major advantage of using this kind of approach is that, as shown by Abbring and Van den Berg (2003), it is not necessary to have a valid instrument for the potential endogenous variable, i.e. in our case parental separation. Identification of the treatment effect does not rely on a conditional independence assumption but comes from the timing of events, i.e. the order in which parental separation and first homelessness occurs. A key assumption in this approach is no-anticipation, i.e. individuals should not know in advance exactly when an event will occur as otherwise they may change their behaviour in anticipation of that event. The no-anticipation assumption does not imply that individuals cannot have an expectation about the likelihood of future events occuring. As long as they do not know in advance when exactly that event occurs, the no-anticipation assumption is not violated. In our analysis of parental separation, the noanticipation assumption allows for the possibility that an individual expects his or her parents to separate in the future but is violated if that individual knows exactly when that separation will occur because that individual may act based on that knowledge. It is unlikely that an individual knows exactly when his parents will separate. The no-anticipation assumption therefore seems reasonable in our analysis.

Identification of the effect of parental separation on the transition to first homelessness also relies on the MPH structure of the hazard rates. However, we use a very flexible specification of the hazard rates as we do not impose functional form assumptions on age dependence or on 
the distribution of unobserved heterogeneity for the hazard rates for parental separation and homelessness.

Our estimation strategy accounts for observable and unobservable characteristics which are time-invariant. Time-varying shocks independently leading to parental separation and homelessness (such as unemployment or the onset of mental illness) remain a threat to our identification. Unfortunately, we do not have information about the timing of events occurring during the respondents' childhood. However, two indirect pieces of evidence suggest that our empirical strategy may be dealing relatively well with (at least) some potential confounders. First, controlling for undated information on caregivers' substance abuse, mental health problems, long-term unemployment, incarceration and gambling issues does not change our estimates on parental separation. Second, McVicar et al. (2017) use the same identification strategy and data to study the effect of substance use on homelessness and find that the effects decrease dramatically or disappear when estimating bivariate mixed proportional hazard models. Given that like parental separation, substance use is strongly correlated with homelessness and its effect could be confounded by the same type of factors, this gives indirect support to the assumption that our duration modelling deals with some of the possible biases.

In our baseline bivariate model there are two transitions. The first is to parental separation, the second is to homelessness. We model transitions up to age 30 to capture parental separation and early onset of homelessness. Parental separation can happen from the birth of the child onwards. The starting rate for parental separation at time $t(t=0$ at age 0$)$ conditional on observed characteristics $x$, and unobserved characteristics $u$ is specified as:

$\theta_{s}(t \mid x, u)=\lambda_{s}(t) \exp \left(x^{\prime} \beta_{s}+u\right)$

where $\lambda_{s}(t)$ represents individual duration dependence. Furthermore, $\beta_{s}$ represents vectors of parameters to be estimated. Unobserved heterogeneity accounts for differences in families' susceptibility to parental separation. So conditional on the observed characteristics there may 
be time-invariant unobserved determinants of the parental separation rate such as the quality of the match between the two parents. We model duration (age) dependence in a flexible way using a step function $\lambda_{s}(t)=\exp \left(\sum_{k} \lambda_{s, k} I_{k}(t)\right)$, where $\mathrm{k}=(1, \ldots, 9)$ is a subscript for age categories and $I_{k}(t)$ are time-varying dummy variables that are one in subsequent categories. We specify 9 age categories, $0-3,4-5,6-7,8-9,10-11,12-13,14-15$, the penultimate one for ages between 16 to 19 and the last interval is for ages from 20 years onwards up to 30 years. Individuals for whom no parental separation occurred by age 30 are assumed to have a rightcensored duration of parental separation. Because we also estimate a constant term, we normalise $\lambda_{s, 1}=0$. All our explanatory variables are described in section 3.2 (see also Table 2).

The conditional density function for the completed durations until the parental separation occurs can be written as

$f_{s}(t \mid x, u)=\theta_{s}(t \mid x, u) \exp \left(-\int_{0}^{t} \theta_{s}(s \mid x, u) d s\right)$

We model the onset of homelessness at time $t$ conditional on observed characteristics $x$, prior parental separation at duration $t_{s}$ and unobserved characteristics $v$ as:

$\theta_{h}\left(t \mid x, t_{s}, v\right)=\lambda_{h}(t) \exp \left(x^{\prime} \beta_{h}+\delta I\left(t_{s}<t\right)+v\right)$

where $I\left(t_{s}<t\right)$ is an indicator function equal to one if parental separation occurred prior to time period $t .{ }^{17}$ Furthermore, $\lambda_{h}(t)$ represents individual duration dependence which is modelled using a step function $\lambda_{h}(t)=\exp \left(\sum_{k} \lambda_{h, k} I_{k}(t)\right)$ which is specified using 12 age intervals: up to age $11,12-13,14,15,16,17,18,19,20-21,22-23,24-26$ and 27 years or older. Individuals who have not experienced homelessness by age 30 are assumed to have a right-censored duration until the onset of homelessness. We normalise $\lambda_{h, 1}=0$. The unobserved heterogeneity represents time-invariant determinants such as the ability of parents to provide sufficient

\footnotetext{
17 As we only know the age at which each event first occurs and not the actual date, we are unable to determine whether parental separation occurred first if both the onset of homelessness and parental separation occurred at the same age. For this reason, we allow parental separation to influence homelessness if and only if it occurred at an earlier age.
} 
financial resources to support the family or the stability of family life. Both observed and unobserved characteristics influence the rate by which an individual becomes homeless.

The effect of parental separation on the onset of homelessness is measured by $\delta$ which may cause a shift in the rate by which individuals become homeless. This is the key parameter of interest as it informs us as to whether previous parental separation increases the risk of homelessness $(\delta>0)$, reduces the risk of homelessness $(\delta<0)$, or has no effect on the likelihood of experiencing homelessness $(\delta=0)$.

The conditional density function for the completed duration until first homelessness can be written as

$f_{h}\left(t \mid x, t_{s}, v\right)=\theta_{h}\left(t \mid x, t_{s}, v\right) \exp \left(-\int_{0}^{t} \theta_{h}\left(h \mid x, t_{s}, v\right) d h\right)$

So far, we have assumed that the effect of parental separation is exogenous to the rate by which individuals become homeless. However, this may not be the case. Some individuals may have unobserved characteristics such that they are both more likely to have parents who are likely to separate and they themselves are more likely to become homeless. If this is the case at least part of the estimated effect of parental separation is in fact caused by correlation in unobserved heterogeneity across the two transitions. In other words, if we simply compare individuals whose parents are separated with individuals whose parents did not separate we are actually comparing individuals whose parents are separated and who are themselves more likely to become homeless anyway with individuals whose parents did not separate and who themselves are less likely to become homeless. Our estimate of the effect of parental separation on the transition into homelessness would then be biased upwards. To correct for this potential source of bias, we account for the potential correlation of unobserved heterogeneity. We do this by specifying the joint density function for the duration until parental separation $t_{s}$ and the duration until homelessness $t_{h}$ conditional on $x$ as:

$f\left(t_{s}, t_{h} \mid x\right)=\int_{u} \int_{v} f_{s}(t \mid x, u) f_{h}\left(t \mid x, t_{s}, v\right) d G(u, v)$ 
$G(u, v)$ is assumed to be a flexible discrete distribution with an unknown number of points of support. We will start assuming that for every transition process unobserved heterogeneity can be specified by a discrete distribution with two points of support. ${ }^{18}$ In combination this leads to four points of support: $\left(u_{1}, v_{1}\right),\left(u_{1}, v_{2}\right),\left(u_{2}, v_{1}\right),\left(u_{2}, v_{2}\right)$, reflecting the finding of two types of individuals in both hazard rates for parental separation (high family susceptibility and low family susceptibility for parental separation) and two types in the hazard rate for homelessness (high susceptibility, low susceptibility). The four mass points imply that conditional on observed characteristics there are four types of individuals. The associated probabilities are denoted as follows:

$\operatorname{Pr}\left(u=u_{1}, v=v_{1}\right)=p_{1} \quad \operatorname{Pr}\left(u=u_{2}, v=v_{1}\right)=p_{2}$

$\operatorname{Pr}\left(u=u_{1}, v=v_{2}\right)=p_{3} \quad \operatorname{Pr}\left(u=u_{2}, v=v_{2}\right)=p_{4}$

with $0 \leq p_{c} \leq 1$ for $c=1-4$. These probabilities are modelled using a multinomial logit specification with $\mathrm{p}_{\mathrm{j}}=\exp \left(\alpha_{\mathrm{j}}\right) / \Sigma_{\mathrm{j}} \exp \left(\alpha_{\mathrm{j}}\right)$, for $\mathrm{j}=1, . ., 4$, normalizing $\alpha_{4}=0$.

The parameter estimates are obtained using the method of maximum likelihood taking into account that our duration information relates to intervals rather than to exact durations. For example, an individual who indicated to have become homeless at age 16 may have become homeless on his $16^{\text {th }}$ birthday or on the day before his $17^{\text {th }}$ birthday. For this individual, we model that he had not yet become homeless at age 15, but had become homeless before turning 17.

\section{$5 \quad$ Results}

Tables 5 and 6 present parameter estimates of mixed proportional hazard models of the duration until parental separation and the duration until homelessness (with durations censored at 30),

\footnotetext{
${ }^{18}$ We also investigated whether the existence of a third mass-point in each of the processes but were not able to identify such a third mass-point.
} 
separately for women and men. The first four columns present estimates for separate models of parental separation and homelessness. The last four columns show results of the joint estimates. The main parameters of interest are the coefficients on parental separation before age 12 and the coefficient on parental separation from 12 to 30 in the equation for homelessness reported in the first two rows of the tables.

For women, parental separation before age 12 increases the risk of homelessness, but if the separation occurs after age 12 , it has no effect on homelessness. The estimates indicate that for respondents whose parents separated before they were 12, the rate of entry into homelessness is more than double the rate of otherwise similar women whose parents did not separate (i.e. a difference of $100(\exp (0.80)-1)=123$ percent). The distribution of unobserved heterogeneity implies that 95 percent of females belong to the Type 1 group, having a positive starting rate for homelessness. Adverse childhood circumstances (not living with parents because of death or conflict and emotional abuse) also increase transitions into homelessness. In contrast the caregivers' level of education does not affect transitions into homelessness.

\section{Table 5 and 6 about here}

Results in which the unobserved components of the transition into parental separation and homelessness are correlated are contained in the last four columns of Table 5 . There is no evidence of a correlation between the unobserved factors affecting parental separation and homelessness, i.e. the joint modelling does not improve on the separate modelling. The null hypothesis of independent unobserved heterogeneity is examined using a Likelihood Ratio test. With a test statistic of 0.3 , the null hypothesis is accepted at the $1 \%$ level suggesting that the unobserved heterogeneities determining the onset of parental separation and homelessness are independent. ${ }^{19}$

19 The LR test statistic for the null hypothesis that the unobserved heterogeneity terms are independent is distributed as a chi-squared with 1 degree of freedom. 
For men, the results differ: parental separation that occurs before and from age 12 increases transitions into homelessness. Here, with a LR-test statistic of 10.3 between the independent and joint models, we reject the null hypothesis at the $1 \%$ level of significance and conclude that the unobserved heterogeneities determining the onset of parental separation and homelessness are not independent. For men, the joint model estimates are therefore preferred and suggest that the rate at which respondents first experience homelessness is greater (than those whose parents did not separate): by 101 percent for those whose parents separated before they were $12(100(\exp (0.70)-1))$; and by 129 percent for those whose parents separated when they were 12 or older $(100(\exp (0.83)-1))$.

The distribution of unobserved heterogeneity implies that $39 \%$ of men belong to the Type 1 group, having a high parental separation occurrence rate and a high starting rate for homelessness (u1, v1); $32 \%$ belong to the Type 2 group with a low parental separation occurrence rate and a high starting rate for homelessness $(u 2, v 1)$; while $6 \%$ are from the Type 3 group and have a high parental separation occurrence rate and a low starting rate for homelessness (u1, v2); finally, 23\% (Type 4) have a low starting rate for both parental separation and homelessness $(\mathrm{u} 2, v 2)$. The identification of four types suggest that controlling for unobserved heterogeneity and taking the timing of events into consideration with the duration modelling is important. As for women, childhood adverse circumstances are found to increase men's transition rate into homelessness.

The stark difference in results by gender is intriguing but not unseen in the literature. For instance, it has been found that parental separation tends to increase boys' behavioural problems but not girls (McLanahan et al., 2013; Bertrand \& Pan, 2013). Also, McVicar et al. (2017) find that taking up daily cannabis use increases the probability of transition into homelessness for young men but not for young women. These results are consistent with each other and suggest that adolescent boys might react more strongly to their parents' separation 
via adopting bad or risky behaviours such as substance use and leaving the parental home without any alternative leading them to homelessness. Of course, this is only one possible sequence of events and other pathways may explain the differential effect of parental separation on homelessness between boys and girls in adolescence (e.g. dropping out of high school).

Based on these findings, the sensitivity analysis that follows focuses on investigating the robustness of the estimated independent homelessness model for women, and of the estimated joint model for men.

\section{Sensitivity Analysis and Extensions}

In this section, we investigate the robustness of our findings by providing a range of sensitivity analyses related to our definitions and modelling decisions. We also distinguish between the effect of parental separation at the end of a marriage and the end of a de-facto relationship. And, we investigate the relevance of several possible channels explaining the effect of parental separation on homelessness. Our main parameter estimates are presented in Tables 7 and 8 .

Table 7 about here

Using information about the type of accommodation respondents have ever lived in before being surveyed in wave 1, we identify respondents who have ever experienced literal homelessness (i.e. who have stayed in crisis accommodation, squatted abandoned buildings, or slept rough). This allows us to test the robustness of our results to a stricter definition of homelessness. Table 7 shows estimates of the effect of parental separation on homelessness for respondents who experienced literal homelessness using linear probability models (as in Tables 3 and 4) and mixed proportional hazards models (as in Tables 5 and 6). Note that the age of onset is the age of onset for broad homelessness as Journeys Home does not provide the age of onset of literal homelessness. Columns 1 and 3 reproduce the main parameter estimates of Tables 3 to 6 to facilitate comparisons while columns 2 and 4 shows the related parameter 
estimates when we focus on a strict definition of homelessness. The results are not very sensitive to the definition of homelessness. The linear probability model results may suggest that parental separation before age 12 progressively lead to precarious housing first and later to literal homelessness as the estimated coefficients on literal homelessness become larger than those on broad homelessness as respondents become older. The mixed proportional hazards model estimates suggest that overall parental separation before age 12 leads to literal homeless slightly more often than broad homelessness (estimate of 0.9 vs 0.8 for girls). In contrast, parental separation after age 12 leads to literal homeless slightly less often than broad homelessness for boys (estimate of 0.66 vs 0.83 ) and has absolutely no effect for girls.

Our main results show separate estimates for the effect of parental separation before age 12 and from age 12. This distinction is to some extent arbitrary so we test our main model against alternative models with: (1) only one treatment effect for parental separation irrespective of the age at which it occurred; (2) three treatment effects (one before age 12; one between 12 and 16; one between 17 and 30); (3) only one treatment effect before age 12; (4) censoring at age 25 instead of age 30; and (5) censoring at age 35 (table 8). For women, the preferred specification is (3) and has only one treatment effect of parental separation occurring up to age 12 , i.e. the effect of parental separation from age 12 is zero. Specifically, a model with only one treatment effect before age 12 performs better than a model with one treatment effect up to 30 (1) (the log likelihood of (3), -1373.6, is significantly larger than that of (1), 1380.8) and better than models adding one or two treatment effects after 12 (the log likelihoods of model (2) and of the separate homelessness model in Table 5 are not better than model (3)). For men, the results suggest that the best specification has only one treatment effect across all ages (1). Model (3) with only one treatment effect before age 12 performs worse (the log likelihood of (3), -3179.8 is significantly smaller than that of (1), -3174.9); and adding one or two treatment effects after age 12 does not improve the performance of the model (the log 
likelihoods of model (2) and of the joint model in Table 6 are not better than model (1)). Given these results, we conduct all further robustness checks on the model used in (3) for women and (1) for men. These results suggest that parental separation increases the rate at which respondents first experience homelessness by 120 percent for women and 108 percent for men. Results of (2) also show that the effect of parental separation decreases with the age at which the parental separation occurs, becoming insignificant from 12 for girls and from 17 for boys. Finally, censoring at 25 or 35 years old instead of 30 years old yields very similar effects of parental separation on homelessness.

Second, the timing of parental separation and homelessness is critical to our identification strategy. To investigate the sensitivity of our main findings to the use of retrospective information and potential misreporting, we conduct our analysis allowing for a longer interval of uncertainty of three years. For example, if an individual indicated that he became homeless at age 16, we allow for the possibility that he in fact became homeless at 15 , 16 or 17 . In other words, we model that he had not yet become homeless at age 14, but had become homeless before turning 18. We model parental separation in the same way. As before, we assume that parental separation can only have an effect if it occurred first, i.e. at least three years before homelessness (in this alternative setting). Specification 6 in Table 8 shows that our results are robust to misreporting of one year in either direction. Indeed, for most individuals there is a substantial age gap between parental separation and homelessness (Figure 3).

Table 8 about here

Third, we distinguish the effect of parental separation between the end of marriages and the end of de facto relationships. De facto relationships may characterise relationships that are less stable than marriages, i.e. in which partners rely less on their partner and protect themselves better against a potential break-up (by working or saving more for example or by not taking a long-term mortgage). As a result, the ending of the partnership may cause less financial distress 
for the partners helping them to avoid homelessness. At the same time, the ending of a marriage may provide more legal financial security to the less advantaged partner than the ending of a de facto relationship and therefore protect her better from homelessness. All in all, conceptually it is unclear whether endings of de facto relationships or marriages have larger effects on homelessness. We divide the main sample into respondents whose parents were/are married (952 observations) and those whose parents were/are in a de facto relationship (279 observations). We run our preferred homelessness models on both subsamples. Essentially, for both boys and girls, the ending of a marriage is worse than that of a de facto relationship. The ending of a marriage more than doubles the transition rates into homelessness and the effects are significant at the $1 \%$ level, while the ending of a de facto relationship does not significantly increase transitions into homelessness (and the magnitude of these coefficients are half those of marriages).

Fourth, we test some possible mechanisms through which parental separation may increase homelessness. Results from the homelessness models in Tables 5 and 6 suggest that several other characteristics relate to homelessness: parents' death; conflict with parents and emotional abuse. If these characteristics result from the parental separation, they could be channels through which parental separation affects homelessness, rather than potential confounding factors. To test this, we run our preferred models removing those characteristics one by one to see if this affects the estimation of the treatment effects. If they act as channels, the effects from parental separation to homelessness should be larger without those controls. We find this is not the case suggesting that those variables are unlikely to be channels through which parental separation leads to homelessness.

Further, we test for other possible mechanisms which could contribute to the effect of parental separation on homelessness: (i) financial difficulties captured by having had utilities disconnected because of unpaid bills during childhood; (ii) family conflict or violence leading 
to the placement of the respondent in State care and (iii) caregivers' difficulties in coping with the separation leading to substance abuse, mental health issues, incarceration, unemployment for more than 6 months or gambling issues. Controls for having had utilities disconnected, having been placed into State care and female caregiver's substance abuse and mental health issues are positively related to the respondent's transition rate into homelessness (except the female caregiver's substance abuse for girls). ${ }^{20}$ However, their introduction only has a very small effect on the estimated treatment effect for parental separation, suggesting these are not channels to homelessness. This absence of finding could either be because these variables are poor proxies for the underlying mechanism or because these variables actually have an independent effect on homelessness. Some of those events or characteristics are also possibly good proxies for time-varying shocks which may have led independently to both parental separation and homelessness (such as an income or wealth shock proxied by having had utilities disconnected or caregivers' long-term unemployment). Although we cannot rule out such shocks completely, the robustness of our results to the introduction of those controls is reassuring.

We also investigate whether the effect of parental separation on homelessness is related to time evolutions, such as the economic cycle for example. Parental separation and homelessness may simultaneously increase in recessions, possibly confounding our estimates. Controlling for the Australian unemployment rate in the calendar year of parental separation to capture the economic cycle, we find no such evidence: although the unemployment rate in the year of parental separation increases transitions into homelessness, it does not alter our baseline estimates of the effect of parental separation (see online Appendix 5 for details). We also

\footnotetext{
${ }^{20}$ Male caregivers' issues do not affect the transition rate of the respondent into homelessness. This is possibly because after a parental separation, most children would stay with their female caregiver rather than their male caregiver. Female caregivers' incarceration, unemployment and gambling issues also have no effect on transitions into homelessness possibly because there are too few cases or because of measurement error.
} 
examine possible birth cohort effects. Introducing an effect for being born from 1980 onwards, we find that earlier birth cohorts have lower transition rates to both homelessness and parental separation. Although this decreases our baseline estimate for women, it remains very significant, and estimates for men are unchanged. Interestingly, interacting the effect of parental separation with the birth cohort dummy, we find that the effect of parental separation on homelessness does not vary over time (see online Appendix 5 for details).

To illustrate the magnitude of the effects of parental separation on the entry into homelessness we perform some simulations based on our preferred parameter estimates in combination with the characteristics of hypothetical reference individuals. Our preferred estimates are those presented in Table 8 (1) for men and (3) for women. For the hypothetical individual, we set all explanatory variables in our analysis to zero. So, the hypothetical individual was not confronted to emotional abuse or physical or sexual violence during childhood and had males and female caregivers with less than primary school education. The top graph of Figure 4 shows the cumulative probability to become homeless by age for our hypothetical woman. The black line gives the evolution for women whose parents did not separate. By age 20 about $10 \%$ of these hypothetical women have become homeless, increasing to a little over $20 \%$ by age 30 . The top line shows the situation in which the parents separated shortly after the birth of the hypothetical girl. Initially, parental separation has a small effect in absolute terms but by age 20 the hypothetical women already has a $20 \%$ probability to have become homeless. By age 30 this is more than $40 \%$. In other words, the effect of parental separation doubles the probability to have become homeless by age 30 . The bottom graph of Figure 4 shows the cumulative probability to become homeless for a different type of hypothetical women. These women were confronted with emotional abuse during childhood and were not living with their parents at age 14 because of conflict. Their cumulative probability to become homeless is much higher. Women whose parents did not separate have a $60 \%$ 
probability to have experienced homelessness by age 20 , which increases to $80 \%$ by age 30 . With an early parental separation, these numbers are substantially higher; i.e. $85 \%$ by age 20 and $95 \%$ by age 30 .

Figure 4 about here

Figure 5 shows similar simulations for males. Since we find that for males it also matters whether their parents separated after age 12 we distinguish five potential situations: no parental separation; parental separations at age $1 ; 12 ; 15$ and 20 . The top graph shows that for men whose parents did not separate the cumulative probability to have experienced homelessness is about $25 \%$ by age 20 which increases to about $50 \%$ by age 30 . There is not much difference between men whose parents separated when they were very young and men whose parents separated when they were 12 or 15 years old. For these groups, the cumulative probability to have become homeless at least once is $40 \%$ by age 20 and $65 \%$ by age 30 . Parental separation occurring when the male is 20 years old increases the male's homelessness onset to the extent that by age 30 they are not very different from men whose parents separated at a very young age. The lower graph of Figure 5 shows similar differences for men who were confronted with emotional abuse and conflicts during their childhood. However, the differences between the different ages of the child at separation are not as large. Men whose parents did not separate have a probability of $80 \%$ to be homeless by age 30 . This is about $90 \%$ in the case of a parental separation, irrespective of whether it occurred when the child was very young or much older.

Figure 5 about here

\section{Conclusions}

Using a unique and detailed dataset on homelessness experiences of disadvantaged Australians, we investigate the effect of childhood experiences of parental separation on entry into homelessness in the short- and medium-run. In theory, parental separation and homelessness could be correlated through observable and unobservable family and individual characteristics. 
Unstable families or families which experience a negative financial shock may also be families that have children that are more likely to make a transition into homelessness. We utilise a bivariate hazard rate framework in which parental separation and entry into homelessness are determined by observable and unobservable characteristics. This allows us to move beyond previous estimates of correlations and make an important contribution towards the establishment of a causal link.

We find that even after accounting for potential observed and unobserved confounders there is a substantial effect of parental separation on the first entry into homelessness. Specifically, if parents separate before the child reaches age 12 the child has a 10-20 percentage point higher probability of experiencing homelessness by age 30 .

Interestingly, we find effects that are not gender neutral. For girls, if their parents separate before they reach age 12 , they are more likely to become homeless. However, if their parents separate after age 12, there is no effect. For boys, the effect of parental separation on their entry into homelessness persists. If the parental separation occurs after age 12 there is still a positive effect on their entry into homelessness. Our results suggest that adolescent girls are more robust to parental separations than adolescent boys, in line with previous literature. Further, we find that the effects of parental separation are larger when the parents were formally married. Taken together these results suggest that policy programs targeting the housing needs of disadvantaged one-parent households can help avoid initiation into homelessness for children living in these families. This would contribute to breaking the intergenerational cycle of disadvantage. More generally, our results give an interesting counterpoint to the literature finding that parental separation has little to no negative consequences on children's wellbeing, once endogeneity is accounted for (see McLanahan et al., 2013 for a review). Indeed, although parental separation may not have a detrimental impact on children's development and education outcomes on average, it appears to deteriorate housing conditions (as suggested by the housing 
literature), to the point of homelessness for very disadvantaged children. This possibly have broader ramifications for those children in terms of education in the long run. 


\section{References}

Abbring, J.H. \& van den Berg, G. (2003). The nonparametric identification of treatment effects in duration models. Econometrica 71, 1491-1517.

Abbring, J.H., van den Berg, G.J. \& van Ours, J.C. (2005). The effect of unemployment insurance sanctions on the transition rate from unemployment to employment. Economic Journal, 115, 602-630.

Australian Institute of Health and Welfare (AIHW) (2011). Government-funded Specialist Homelessness Services: SAAP National Data Collection Annual Report 2009-10: Australia (AIHW cat. no. HOU 246), Canberra, AIHW.

Bedard, K. \& Deschenes, O. (2005). Sex preferences, marital dissolution, and the economic status of women. Journal of Human Resources, 40(2), 411-434.

Bertrand, M., \& Pan, J. (2013). The trouble with boys: Social influences and the gender gap in disruptive behavior. American Economic Journal: Applied Economics, 5(1), 32-64.

Boyle, P.J., Kulu, H., Cooke, T., Gayle, V., \& Mulder, C.H. (2008). Moving and union dissolution. Demography, 45(1), 209-222.

Brewin, C. R., Andrews, B., \& Gotlib, I. H. (1993). Psychopathology and early experience: a reappraisal of retrospective reports. Psychological bulletin, 113(1), 82.

Cherlin, A.J., Furstenberg, F.F., Chase-Lansdale, L., Kiernan, K.E., Robins, P.K., Morrison, D.R., \& Teitler, J.O. (1991). Longitudinal studies of effects of divorce on children in Great Britain and the United States. Science, 252(5011), 1386-1389.

Cobb-Clark, D.A., Herault, N., Scutella, R. \& Tseng,Y (2016) A journey home: What drives how long people are homeless?, Journal of Urban Economics, 91, 57-72.

Corno, L. (2017). Homelessness and crime: Do your friends matter?. The Economic Journal, 127(602), 959-995.

Curtis, M.A., Corman, H., Noonan, K. \& Reichman. N.E. (2013). Life shocks and homelessness. Demography, 50, 2227-2253.

Dewilde, C. (2008). Divorce and the housing movements of owner-occupiers: A European comparison. Housing Studies, 23, 809-832.

Ermisch, J., Francesconi, M., \& Pevalin, D.J. (2004). Parental partnership and joblessness in childhood and their influence on young people's outcomes. Journal of the Royal Statistical Society: Series A (Statistics in Society), 167(1), 69-101.

Evenhouse, E., \& Reilly, S. (2004). A sibling study of stepchild well-being. Journal of Human Resources, 39(1), 248-276.

Feijten, P. (2005). Union dissolution, unemployment and moving out of homeownership. European Sociological Review, 21, 59-71.

Feijten, P. \& van Ham, M. (2010). The impact of splitting up and divorce on housing careers in the UK. Housing Studies, 25(4), 483-507.

Finlay, K., \& Neumark, D. (2010). Is marriage always good for children? Evidence from families affected by incarceration. Journal of Human Resources, 45(4), 1046-1088.

Firdion, J-M. \& Marpsat, M. (2007). A research program on homelessness in France. Journal of Social Issues, 63, 567-587. 
Flatau, P., Hendershott, P., Watson, R. \& Wood, G. (2004). What drives Australian housing careers? An examination of the role of labour market, social and economic determinants. Final Report, AHURI.

Gertler, P., Levine, D.I., \& Ames, M. (2004). Schooling and parental death. Review of Economics and Statistics, 86(1), 211-225.

Greene, J. M., Ennett, S. T., \& Ringwalt, C. L. (1997). Substance use among runaway and homeless youth in three national samples. American Journal of Public Health, 87(2), 229235.

Gruber, J. (2004). Is making divorce easier bad for children? The long-run implications of unilateral divorce. Journal of Labor Economics, 22(4), 799-833.

Hardt, J., \& Rutter, M. (2004). Validity of adult retrospective reports of adverse childhood experiences: review of the evidence. Journal of child psychology and psychiatry, 45(2), 260-273.

Headey, B.W., Warren, D. and Harding, G., 2006, Families, Incomes and Jobs: A Statistical Report of the HILDA Survey, Melbourne Institute of Applied Economic and Social Research, Melbourne.

Hladikova, A. \& Hradecky, I. (2007). Homelessness in the Czech Republic. Journal of Social Issues, 63, 607-623.

Johnson, G. \& Chamberlain, C. (2008). Homelessness and substance abuse: which comes first? Australian Social Work, 61(4), 342-356.

Lang, K., \& Zagorsky, J.L. (2001). Does growing up with a parent absent really hurt? Journal of Human Resources, 36(2), 253-273.

Leigh, A. (2009). Does child gender affect marital status? Evidence from Australia. Journal of Population Economics, 22(2), 351-366.

Link, B.G., Susser, E., Stueve, A., Phelan, J., Moore, R.E. \& Struening, E. (1994). Lifetime and five-year prevalence of homelessness in the United States. American Journal of Public Health, 84, 1907-1912.

McLanahan, S., Tach, L. \& Schneider, D. (2013). The causal effects of father absence. Annual Review of Sociology, 39, 399-427.

McVicar, D., Moschion, J. \& van Ours, J.C. (2015). From substance use to homelessness or vice versa? Social Science and Medicine, 136, 89-98.

McVicar, D., Moschion, J. \& van Ours, J.C. (2017). Early substance use and the age of onset of homelessness. Mimeo.

Melbourne Institute (2012). Journeys Home Wave 1 Technical Report - Sample, Fieldwork, Response and Weighting (Report prepared for the Australian Government Department of Families, Housing, Community Services and Indigenous Affairs).

Mulder, C.H. \& Lauster, N.T. (2010). Housing and family: An introduction. Housing Studies, 25(4), 433-440.

O'Flaherty, B. (2004). Wrong person and wrong place: For homelessness, the conjunction is what matters. Journal of Housing Economics, 13(1), 1-15.

O'Flaherty, B. (2009). What shocks precipitate homelessness? Unpublished manuscript. New York: Columbia University. 
O'Flaherty, B. (2010). Homelessness as bad luck: Implications for research and policy. In I.G. Ellen \& B. O'Flaherty (Eds.) How to House the Homeless. New York: Russell Sage Foundation, 143-182.

Okamoto, Y. (2007). A comparative study of homelessness in the United Kingdom and Japan. Journal of Social Issues, 63, 525-542.

Philippot, P., Lecocq, C., Sempoux, F., Nachtergael, H., \& Galand, B. (2007). Psychological research on homelessness in Western Europe: A review from 1970 to 2001. Journal of Social Issues, 63, 483-503.

Rog, D. J., \& Buckner, J. C. (2007). Homeless families and children. In Toward understanding homelessness: The 2007 national symposium on homelessness research. Washington, DC: US Department of Housing and Urban Development.

Sedlack, A. J., Finkelhor, D., Hammer, H., \& Schultz, D. (2002). National Estimates of Missing Children: An Overview. NISMART Series Bulletin.

Scutella, R., Johnson, G., Moschion, J., Tseng, Y. \& Wooden M. (2012). "Journeys Home” Research Report 1, Report prepared for the Australian Government Department of Families, Housing, Community Services and Indigenous Affairs.

Shinn, M., Gottlieb, J., Wett, J.L., Bahl, A., Cohen, A., \& Ellis, D.B. (2007). Predictors of homelessness among older adults in New York City disability, economic, human and social capital and stressful events. Journal of Health Psychology, 12(5), 696-708.

Toro, P. A., Dworsky, A., \& Fowler, P. J. (2007). Homeless youth in the United States: Recent research findings and intervention approaches. In National symposium on homelessness research

Van den Berg, G.J., van der Klaauw, J.C. \& van Ours, J.C. (2004). Punitive sanctions and the transition rate from welfare to work. Journal of Labor Economics, 22(1), 211-241.

Van Ours, J.C. \& Williams, J. (2015). Cannabis use and its effects on health, education and labor market success. Journal of Economic Surveys, 29 (5), 993-1010.

Wooden, M., Bevitt, A., Chigavazira, A., Greer, N., Johnson, G., Killackey, E., Moschion, J., Scutella, R., Tseng, Y.-P. and Watson, N. (2012), Introducing 'Journeys Home'. Australian Economic Review, 45: 368-378. 
Table 1: Prevalence and onset of parental separation and homelessness up to age 30

\begin{tabular}{|c|c|c|}
\hline & Women & Men \\
\hline \multicolumn{3}{|l|}{ Homelessness } \\
\hline \multirow[t]{2}{*}{ Ever $(\%)$} & 73.9 & 71.7 \\
\hline & $(43.9)$ & $(45.1)$ \\
\hline \multirow[t]{2}{*}{ Age onset } & 17.5 & 17.6 \\
\hline & $(5.0)$ & $(5.0)$ \\
\hline \multicolumn{3}{|l|}{ Homelessness types (ever in \%) } \\
\hline \multirow[t]{2}{*}{ With relatives with no alternatives } & 60.3 & 55.6 \\
\hline & $(49.0)$ & $(49.7)$ \\
\hline \multirow[t]{2}{*}{ With friends with no alternatives } & 59.0 & 61.0 \\
\hline & $(49.2)$ & $(48.8)$ \\
\hline \multirow[t]{2}{*}{ In a caravan park } & 28.2 & 33.5 \\
\hline & $(45.0)$ & $(47.2)$ \\
\hline \multirow[t]{2}{*}{ In a boarding house } & 26.2 & 37.8 \\
\hline & $(44.0)$ & $(48.5)$ \\
\hline \multirow[t]{2}{*}{ In a hotel $/$ motel } & 33.0 & 34.6 \\
\hline & $(47.1)$ & $(47.6)$ \\
\hline \multirow[t]{2}{*}{ In crisis accommodation } & 33.3 & 32.6 \\
\hline & $(47.2)$ & $(46.9)$ \\
\hline \multirow[t]{2}{*}{ Squatting in abandoned buildings } & 15.8 & 29.5 \\
\hline & $(36.5)$ & $(45.7)$ \\
\hline \multirow[t]{2}{*}{ Sleeping rough } & 34.6 & 51.6 \\
\hline & $(47.6)$ & $(50.0)$ \\
\hline \multirow[t]{2}{*}{ Precariously housed } & 73.0 & 70.0 \\
\hline & $(44.4)$ & $(45.9)$ \\
\hline \multirow{2}{*}{ Literally homeless } & 48.8 & 56.1 \\
\hline & $(50.0)$ & $(49.7)$ \\
\hline \multicolumn{3}{|l|}{ Parental separation } \\
\hline \multirow[t]{2}{*}{ Ever $(\%)$} & 64.7 & 56.7 \\
\hline & $(47.8)$ & (49.6) \\
\hline \multirow[t]{2}{*}{ Age onset } & 7.3 & 8.3 \\
\hline & $(6.2)$ & $(6.7)$ \\
\hline $\mathrm{N}$ & 564 & 667 \\
\hline
\end{tabular}

Notes: Wave 1 and 6 respondents with information on parental separation and homelessness (1,231 observations). Only homeless spells and parental separations occurring before 30 are considered. The ages of onset are calculated conditional on homelessness occurring or parental separation occurring.

The types of homelessness do not sum up to $100 \%$ as the same respondent may have experienced several types of homelessness. Precarious housing is defined as having stayed with relatives or friends with no alternatives, having stayed in a caravan park, in a boarding house or in a hotel/motel. Literal homelessness is defined as having stayed in crisis accommodation, squatted in abandoned buildings or slept rough. 
Table 2: Sample Characteristics (\%)

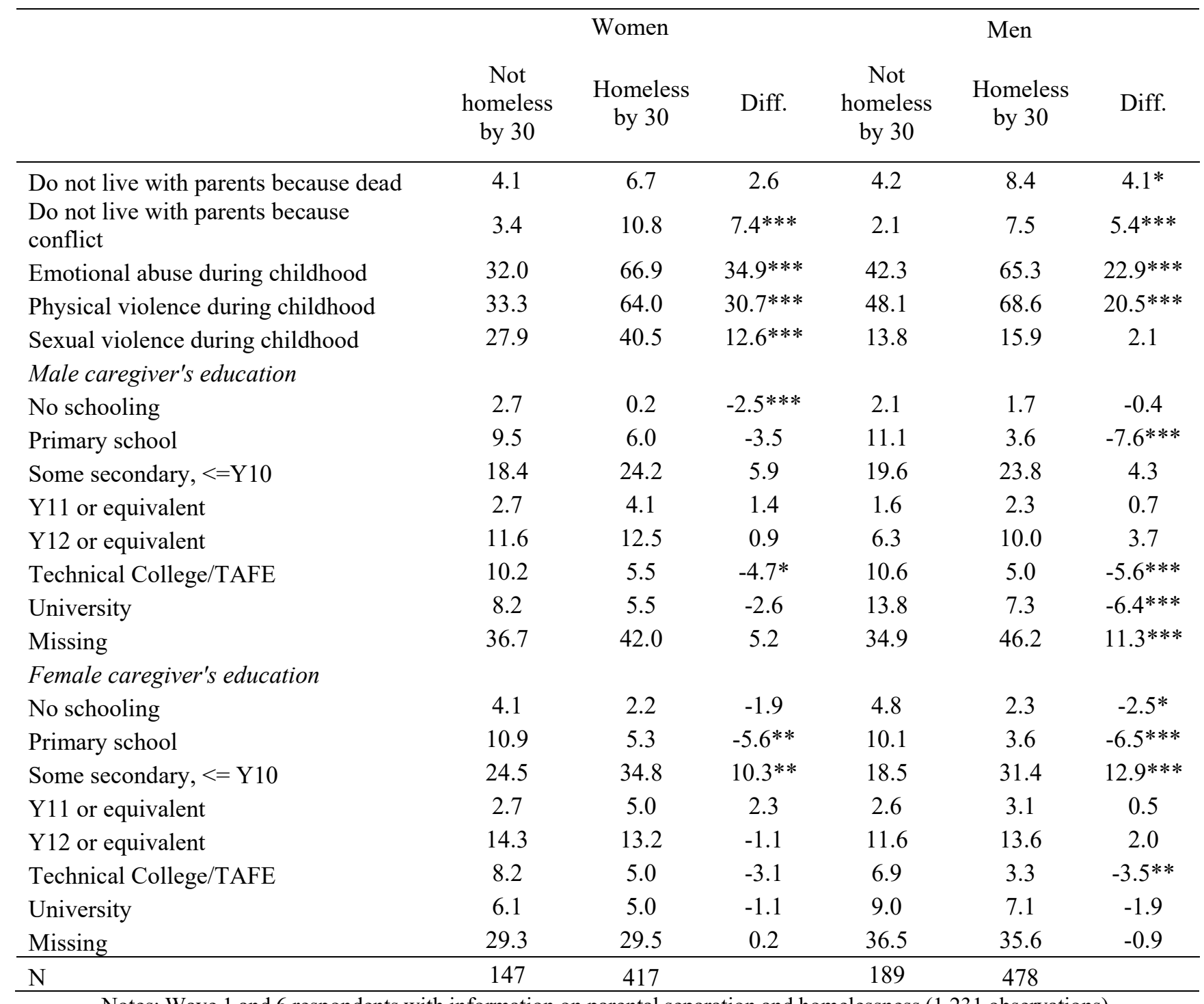

Notes: Wave 1 and 6 respondents with information on parental separation and homelessness (1,231 observations). 
Table 3: Regression estimates of the effect of parental separation before age 12, women

\begin{tabular}{|c|c|c|c|c|}
\hline Homeless & $<=15$ & $<=20$ & $<=25$ & $<=30$ \\
\hline Separation before age 12 & $\begin{array}{c}0.133 * * * \\
(0.039)\end{array}$ & $\begin{array}{c}0.251 * * * \\
(0.043)\end{array}$ & $\begin{array}{c}0.245^{* * *} * \\
(0.039)\end{array}$ & $\begin{array}{c}0.217 * * * \\
(0.035)\end{array}$ \\
\hline \multicolumn{5}{|l|}{ Childhood } \\
\hline Parents dead & $\begin{array}{c}0.126 \\
(0.083)\end{array}$ & $\begin{array}{c}0.073 \\
(0.085)\end{array}$ & $\begin{array}{l}0.140^{*} \\
(0.075)\end{array}$ & $\begin{array}{c}0.106 \\
(0.070)\end{array}$ \\
\hline Conflict parents & $\begin{array}{c}0.384 * * * \\
(0.066)\end{array}$ & $\begin{array}{c}0.190 * * * \\
(0.061)\end{array}$ & $\begin{array}{l}0.104^{*} \\
(0.060)\end{array}$ & $\begin{array}{l}0.080^{*} \\
(0.046)\end{array}$ \\
\hline Emotional abuse & $\begin{array}{c}0.086 \\
(0.055)\end{array}$ & $\begin{array}{c}0.245^{* * *} * \\
(0.070)\end{array}$ & $\begin{array}{c}0.200 * * * \\
(0.064)\end{array}$ & $\begin{array}{c}0.177 * * * \\
(0.061)\end{array}$ \\
\hline Physical violence & $\begin{array}{c}0.124 * * \\
(0.057)\end{array}$ & $\begin{array}{c}0.045 \\
(0.071)\end{array}$ & $\begin{array}{c}0.048 \\
(0.063)\end{array}$ & $\begin{array}{c}0.038 \\
(0.061)\end{array}$ \\
\hline Sexual violence & $\begin{array}{c}0.057 \\
(0.045)\end{array}$ & $\begin{array}{l}-0.030 \\
(0.046)\end{array}$ & $\begin{array}{l}-0.051 \\
(0.043)\end{array}$ & $\begin{array}{l}-0.025 \\
(0.041)\end{array}$ \\
\hline \multicolumn{5}{|l|}{ Male caregiver's education } \\
\hline Primary school & $\begin{array}{l}-0.003 \\
(0.069)\end{array}$ & $\begin{array}{c}-0.118 \\
(0.215)\end{array}$ & $\begin{array}{c}0.073 \\
(0.223)\end{array}$ & $\begin{array}{c}0.307 \\
(0.231)\end{array}$ \\
\hline Some secondary, $<=\mathrm{Y} 10$ & $\begin{array}{c}0.018 \\
(0.081)\end{array}$ & $\begin{array}{c}0.046 \\
(0.214)\end{array}$ & $\begin{array}{c}0.239 \\
(0.220)\end{array}$ & $\begin{array}{c}0.339 \\
(0.226)\end{array}$ \\
\hline Y11 or equivalent & $\begin{array}{l}-0.097 \\
(0.126)\end{array}$ & $\begin{array}{l}-0.085 \\
(0.244)\end{array}$ & $\begin{array}{c}0.166 \\
(0.248)\end{array}$ & $\begin{array}{c}0.357 \\
(0.239)\end{array}$ \\
\hline Y12 or equivalent & $\begin{array}{c}-0.004 \\
(0.090)\end{array}$ & $\begin{array}{c}0.013 \\
(0.219)\end{array}$ & $\begin{array}{c}0.217 \\
(0.224)\end{array}$ & $\begin{array}{c}0.322 \\
(0.229)\end{array}$ \\
\hline Technical College/TAFE & $\begin{array}{c}-0.032 \\
(0.099)\end{array}$ & $\begin{array}{c}-0.183 \\
(0.224)\end{array}$ & $\begin{array}{c}0.026 \\
(0.229)\end{array}$ & $\begin{array}{c}0.198 \\
(0.233)\end{array}$ \\
\hline University & $\begin{array}{l}-0.039 \\
(0.090)\end{array}$ & $\begin{array}{l}-0.072 \\
(0.222)\end{array}$ & $\begin{array}{c}0.075 \\
(0.228)\end{array}$ & $\begin{array}{c}0.250 \\
(0.232)\end{array}$ \\
\hline Missing & $\begin{array}{l}-0.002 \\
(0.077)\end{array}$ & $\begin{array}{l}-0.022 \\
(0.214)\end{array}$ & $\begin{array}{c}0.137 \\
(0.219)\end{array}$ & $\begin{array}{c}0.288 \\
(0.224)\end{array}$ \\
\hline \multicolumn{5}{|l|}{ Female caregiver's education } \\
\hline Primary school & $\begin{array}{l}-0.044 \\
(0.092)\end{array}$ & $\begin{array}{l}-0.032 \\
(0.133)\end{array}$ & $\begin{array}{c}-0.055 \\
(0.135)\end{array}$ & $\begin{array}{l}-0.114 \\
(0.138)\end{array}$ \\
\hline Some secondary, $<=\mathrm{Y} 10$ & $\begin{array}{c}0.053 \\
(0.092)\end{array}$ & $\begin{array}{c}0.083 \\
(0.120)\end{array}$ & $\begin{array}{c}0.088 \\
(0.118)\end{array}$ & $\begin{array}{c}0.050 \\
(0.116)\end{array}$ \\
\hline Y11 or equivalent & $\begin{array}{c}0.132 \\
(0.123)\end{array}$ & $\begin{array}{l}0.246^{*} \\
(0.136)\end{array}$ & $\begin{array}{c}0.134 \\
(0.130)\end{array}$ & $\begin{array}{c}0.071 \\
(0.123)\end{array}$ \\
\hline Y12 or equivalent & $\begin{array}{c}0.133 \\
(0.101)\end{array}$ & $\begin{array}{c}0.111 \\
(0.125)\end{array}$ & $\begin{array}{c}0.017 \\
(0.122)\end{array}$ & $\begin{array}{l}-0.057 \\
(0.121)\end{array}$ \\
\hline Technical College/TAFE & $\begin{array}{l}-0.109 \\
(0.110)\end{array}$ & $\begin{array}{c}0.082 \\
(0.140)\end{array}$ & $\begin{array}{c}0.053 \\
(0.139)\end{array}$ & $\begin{array}{l}-0.061 \\
(0.138)\end{array}$ \\
\hline University & $\begin{array}{c}0.122 \\
(0.115)\end{array}$ & $\begin{array}{c}0.117 \\
(0.142)\end{array}$ & $\begin{array}{l}-0.018 \\
(0.142)\end{array}$ & $\begin{array}{l}-0.051 \\
(0.140)\end{array}$ \\
\hline Missing & $\begin{array}{c}0.065 \\
(0.093)\end{array}$ & $\begin{array}{c}0.088 \\
(0.122)\end{array}$ & $\begin{array}{c}0.017 \\
(0.119)\end{array}$ & $\begin{array}{l}-0.041 \\
(0.118)\end{array}$ \\
\hline \multicolumn{5}{|l|}{ Missing info } \\
\hline Reason not living with parents & $\begin{array}{c}0.173 \\
(0.151)\end{array}$ & $\begin{array}{c}0.231 \\
(0.177)\end{array}$ & $\begin{array}{c}0.132 \\
(0.178)\end{array}$ & $\begin{array}{c}0.280 * * \\
(0.129)\end{array}$ \\
\hline Violence & $\begin{array}{l}0.102^{*} \\
(0.055)\end{array}$ & $\begin{array}{c}0.003 \\
(0.061)\end{array}$ & $\begin{array}{c}-0.008 \\
(0.059)\end{array}$ & $\begin{array}{c}0.042 \\
(0.056)\end{array}$ \\
\hline $\mathrm{N}$ & 547 & 528 & 522 & 518 \\
\hline
\end{tabular}

Notes: We remove from the sample homeless spells occurring before age 12; the number of observation decreases from one column to the next because of right censored observations due to age restrictions; robust standard errors in parentheses; $* * * / * * / *$ indicates significance at a $1 / 5 / 10 \%$-level. 
Table 4: Regression estimates of the effect of parental separation before age 12, men

\begin{tabular}{|c|c|c|c|c|}
\hline Homeless & $<=15$ & $<=20$ & $<=25$ & $<=30$ \\
\hline Separation before age 12 & $\begin{array}{c}0.115 * * * \\
(0.035)\end{array}$ & $\begin{array}{c}0.251 * * * \\
(0.041)\end{array}$ & $\begin{array}{c}0.263 * * * \\
(0.036)\end{array}$ & $\begin{array}{c}0.229 * * * \\
(0.033)\end{array}$ \\
\hline \multicolumn{5}{|l|}{ Childhood } \\
\hline Parents dead & $\begin{array}{c}0.137^{*} \\
(0.070)\end{array}$ & $\begin{array}{c}0.201 * * * \\
(0.067)\end{array}$ & $\begin{array}{l}0.127^{*} \\
(0.066)\end{array}$ & $\begin{array}{l}0.104^{*} \\
(0.061)\end{array}$ \\
\hline Conflict parents & $\begin{array}{c}0.283 * * * \\
(0.088)\end{array}$ & $\begin{array}{c}0.064 \\
(0.080)\end{array}$ & $\begin{array}{c}0.051 \\
(0.074)\end{array}$ & $\begin{array}{c}0.044 \\
(0.059)\end{array}$ \\
\hline Emotional abuse & $\begin{array}{c}0.065 \\
(0.041)\end{array}$ & $\begin{array}{c}0.138 * * \\
(0.058)\end{array}$ & $\begin{array}{l}0.090^{*} \\
(0.055)\end{array}$ & $\begin{array}{c}0.122 * * \\
(0.050)\end{array}$ \\
\hline Physical violence & $\begin{array}{c}0.099 * * \\
(0.041)\end{array}$ & $\begin{array}{c}0.083 \\
(0.058)\end{array}$ & $\begin{array}{c}0.041 \\
(0.055)\end{array}$ & $\begin{array}{c}0.018 \\
(0.050)\end{array}$ \\
\hline Sexual violence & $\begin{array}{c}0.001 \\
(0.047)\end{array}$ & $\begin{array}{l}-0.035 \\
(0.055)\end{array}$ & $\begin{array}{l}-0.062 \\
(0.055)\end{array}$ & $\begin{array}{c}-0.033 \\
(0.050)\end{array}$ \\
\hline \multicolumn{5}{|l|}{ Male caregiver's education } \\
\hline Primary school & $\begin{array}{c}-0.038 \\
(0.127)\end{array}$ & $\begin{array}{c}-0.072 \\
(0.137)\end{array}$ & $\begin{array}{c}-0.196 \\
(0.152)\end{array}$ & $\begin{array}{c}-0.154 \\
(0.151)\end{array}$ \\
\hline Some secondary, $<=$ Y10 & $\begin{array}{c}-0.113 \\
(0.130)\end{array}$ & $\begin{array}{c}0.001 \\
(0.126)\end{array}$ & $\begin{array}{l}-0.060 \\
(0.138)\end{array}$ & $\begin{array}{l}-0.014 \\
(0.137)\end{array}$ \\
\hline Y11 or equivalent & $\begin{array}{c}-0.078 \\
(0.160)\end{array}$ & $\begin{array}{l}-0.067 \\
(0.176)\end{array}$ & $\begin{array}{l}-0.065 \\
(0.172)\end{array}$ & $\begin{array}{l}-0.024 \\
(0.164)\end{array}$ \\
\hline Y12 or equivalent & $\begin{array}{l}-0.037 \\
(0.138)\end{array}$ & $\begin{array}{c}0.051 \\
(0.135)\end{array}$ & $\begin{array}{c}0.004 \\
(0.143)\end{array}$ & $\begin{array}{c}0.047 \\
(0.142)\end{array}$ \\
\hline Technical College/TAFE & $\begin{array}{l}-0.126 \\
(0.134)\end{array}$ & $\begin{array}{l}-0.110 \\
(0.140)\end{array}$ & $\begin{array}{l}-0.095 \\
(0.153)\end{array}$ & $\begin{array}{l}-0.101 \\
(0.153)\end{array}$ \\
\hline University & $\begin{array}{l}-0.040 \\
(0.137)\end{array}$ & $\begin{array}{l}-0.096 \\
(0.133)\end{array}$ & $\begin{array}{l}-0.177 \\
(0.144)\end{array}$ & $\begin{array}{l}-0.137 \\
(0.145)\end{array}$ \\
\hline Missing & $\begin{array}{c}0.004 \\
(0.130)\end{array}$ & $\begin{array}{c}0.038 \\
(0.121)\end{array}$ & $\begin{array}{c}-0.011 \\
(0.133)\end{array}$ & $\begin{array}{l}-0.022 \\
(0.133)\end{array}$ \\
\hline \multicolumn{5}{|l|}{ Female caregiver's education } \\
\hline Primary school & $\begin{array}{c}0.083 \\
(0.082)\end{array}$ & $\begin{array}{l}-0.093 \\
(0.119)\end{array}$ & $\begin{array}{l}-0.080 \\
(0.131)\end{array}$ & $\begin{array}{l}-0.044 \\
(0.136)\end{array}$ \\
\hline Some secondary, $<=\mathrm{Y} 10$ & $\begin{array}{c}0.133 \\
(0.081)\end{array}$ & $\begin{array}{c}0.240 * * \\
(0.106)\end{array}$ & $\begin{array}{c}0.243 * * \\
(0.117)\end{array}$ & $\begin{array}{c}0.197 \\
(0.120)\end{array}$ \\
\hline Y11 or equivalent & $\begin{array}{c}0.128 \\
(0.123)\end{array}$ & $\begin{array}{c}0.157 \\
(0.154)\end{array}$ & $\begin{array}{c}0.234 \\
(0.161)\end{array}$ & $\begin{array}{c}0.218 \\
(0.153)\end{array}$ \\
\hline Y12 or equivalent & $\begin{array}{c}0.083 \\
(0.087)\end{array}$ & $\begin{array}{c}0.176 \\
(0.111)\end{array}$ & $\begin{array}{c}0.171 \\
(0.121)\end{array}$ & $\begin{array}{c}0.159 \\
(0.124)\end{array}$ \\
\hline Technical College/TAFE & $\begin{array}{c}0.055 \\
(0.098)\end{array}$ & $\begin{array}{c}0.150 \\
(0.132)\end{array}$ & $\begin{array}{c}0.034 \\
(0.141)\end{array}$ & $\begin{array}{c}-0.030 \\
(0.145)\end{array}$ \\
\hline University & $\begin{array}{c}0.105 \\
(0.097)\end{array}$ & $\begin{array}{c}0.187 \\
(0.120)\end{array}$ & $\begin{array}{l}0.223^{*} \\
(0.128)\end{array}$ & $\begin{array}{c}0.201 \\
(0.132)\end{array}$ \\
\hline Missing & $\begin{array}{c}0.090 \\
(0.081)\end{array}$ & $\begin{array}{c}0.121 \\
(0.103)\end{array}$ & $\begin{array}{c}0.127 \\
(0.116)\end{array}$ & $\begin{array}{c}0.122 \\
(0.119)\end{array}$ \\
\hline \multicolumn{5}{|l|}{ Missing info } \\
\hline Reason not living with parents & $\begin{array}{c}0.191 \\
(0.147)\end{array}$ & $\begin{array}{l}-0.140 \\
(0.149)\end{array}$ & $\begin{array}{l}-0.063 \\
(0.158)\end{array}$ & $\begin{array}{l}-0.123 \\
(0.153)\end{array}$ \\
\hline Violence & $\begin{array}{c}0.029 \\
(0.063)\end{array}$ & $\begin{array}{c}0.081 \\
(0.068)\end{array}$ & $\begin{array}{c}0.076 \\
(0.062)\end{array}$ & $\begin{array}{l}0.095^{*} \\
(0.054)\end{array}$ \\
\hline $\mathrm{N}$ & 639 & 627 & 613 & 607 \\
\hline
\end{tabular}

Notes: We remove from the sample homeless spells occurring before age 12; the number of observation decreases from one column to the next because of right censored observations due to age restrictions; robust standard errors in parentheses; $* * * / * * / *$ indicates significance at a $1 / 5 / 10 \%$-level. 
Table 5: Parameter estimates mixed proportional hazards model, parental separation and homelessness, women

\begin{tabular}{|c|c|c|c|c|c|c|c|c|}
\hline \multirow[b]{3}{*}{ Separation before age 12} & \multicolumn{4}{|c|}{ Separate } & \multicolumn{4}{|c|}{ Joint } \\
\hline & \multicolumn{2}{|c|}{$\begin{array}{c}\text { Parental } \\
\text { separation }\end{array}$} & \multicolumn{2}{|c|}{ Homelessness } & \multicolumn{2}{|c|}{$\begin{array}{l}\text { Parental } \\
\text { separation }\end{array}$} & \multicolumn{2}{|c|}{ Homelessness } \\
\hline & & & $0.80 * * *$ & $(0.13)$ & & & $0.86^{* * *}$ & $(0.13)$ \\
\hline Separation from age 12 to 30 & & & 0.07 & $(0.20)$ & & & 0.14 & $(0.21)$ \\
\hline \multicolumn{9}{|l|}{ Childhood } \\
\hline Parents dead & & & $0.50 * *$ & $(0.20)$ & & & $0.45 * *$ & $(0.20)$ \\
\hline Conflict parents & & & $1.30 * * *$ & $(0.20)$ & & & $1.30 * * *$ & $(0.21)$ \\
\hline Emotional abuse & 0.21 & $(0.20)$ & $0.69 * * *$ & $(0.19)$ & 0.21 & $(0.21)$ & $0.68 * * *$ & $(0.19)$ \\
\hline Physical violence & 0.17 & $(0.21)$ & 0.30 & $(0.18)$ & 0.17 & $(0.22)$ & 0.30 & $(0.18)$ \\
\hline Sexual violence & 0.11 & $(0.15)$ & 0.05 & $(0.13)$ & 0.11 & $(0.16)$ & 0.05 & $(0.13)$ \\
\hline \multicolumn{9}{|l|}{ Missing info } \\
\hline Reason not living with parents & & & $0.84 *$ & $(0.46)$ & & & $0.87 *$ & $(0.47)$ \\
\hline Violence & $-0.39^{*}$ & $(0.20)$ & 0.23 & $(0.17)$ & $-0.38 *$ & $(0.21)$ & 0.24 & $(0.17)$ \\
\hline \multicolumn{9}{|l|}{ Male caregiver's education } \\
\hline Primary school & -0.12 & $(1.26)$ & 0.85 & $(1.06)$ & -0.10 & $(6.87)$ & 0.86 & $(5.91)$ \\
\hline Some secondary, $<=Y 10$ & 1.09 & $(1.24)$ & 1.13 & $(1.06)$ & 1.09 & $(6.88)$ & 1.10 & $(5.91)$ \\
\hline Y11 or equivalent & 1.06 & $(1.30)$ & 0.86 & $(1.08)$ & 1.08 & $(6.89)$ & 0.85 & $(5.91)$ \\
\hline Y12 or equivalent & 1.32 & $(1.24)$ & 1.10 & $(1.06)$ & 1.32 & $(6.87)$ & 1.06 & $(5.91)$ \\
\hline Technical College/TAFE & 0.61 & $(1.26)$ & 0.36 & $(1.08)$ & 0.62 & $(6.88)$ & 0.34 & $(5.91)$ \\
\hline University & 0.14 & $(1.27)$ & 0.82 & $(1.09)$ & 0.15 & $(6.88)$ & 0.82 & $(5.92)$ \\
\hline Missing & 1.58 & $(1.24)$ & 0.88 & $(1.06)$ & 1.58 & $(6.87)$ & 0.85 & $(5.91)$ \\
\hline \multicolumn{9}{|l|}{ Female caregiver's education } \\
\hline Primary school & 0.65 & $(0.64)$ & -0.31 & $(0.61)$ & 0.63 & $(0.67)$ & -0.32 & $(0.62)$ \\
\hline Some secondary, $<=Y 10$ & $1.07 *$ & $(0.56)$ & 0.10 & $(0.57)$ & $1.06^{*}$ & $(0.59)$ & 0.08 & $(0.58)$ \\
\hline Y11 or equivalent & 1.03 & $(0.65)$ & 0.47 & $(0.63)$ & 1.02 & $(0.68)$ & 0.45 & $(0.63)$ \\
\hline Y12 or equivalent & $1.77 * * *$ & $(0.58)$ & 0.08 & $(0.59)$ & $1.76^{* * *}$ & $(0.60)$ & 0.07 & $(0.60)$ \\
\hline Technical College/TAFE & 0.75 & $(0.63)$ & -0.23 & $(0.62)$ & 0.73 & $(0.66)$ & -0.25 & $(0.64)$ \\
\hline University & $2.23 * * *$ & $(0.62)$ & 0.13 & $(0.61)$ & $2.22 * * *$ & $(0.64)$ & 0.13 & $(0.62)$ \\
\hline Missing & $1.46^{* * *}$ & $(0.62)$ & -0.04 & $(0.57)$ & $1.44 * *$ & $(0.59)$ & -0.06 & $(0.58)$ \\
\hline Constant & $-4.78 * * *$ & $(1.33)$ & $-8.17 * * *$ & $(1.16)$ & -4.77 & $(6.95)$ & -8.15 & $(5.86)$ \\
\hline \multicolumn{9}{|l|}{ Age (separation / homelessness) } \\
\hline $4-5 / 12-13$ years old & -0.28 & $(0.17)$ & $2.48 * * *$ & $(0.30)$ & -0.28 & $(0.18)$ & $2.47 * * *$ & $(0.31)$ \\
\hline $6-7 / 14$ years old & -0.24 & $(0.19)$ & $3.63 * * *$ & $(0.29)$ & -0.24 & $(0.20)$ & $3.62 * * *$ & $(0.30)$ \\
\hline $8-9 / 15$ years old & -0.31 & $(0.21)$ & $4.16^{* * *}$ & $(0.28)$ & -0.30 & $(0.22)$ & $4.14 * * *$ & $(0.29)$ \\
\hline $10-11 / 16$ years old & -0.15 & $(0.22)$ & $4.20 * * *$ & $(0.29)$ & -0.14 & $(0.23)$ & $4.18 * * *$ & $(0.30)$ \\
\hline $12-13 / 17$ years old & 0.18 & $(0.23)$ & $4.31 * * *$ & $(0.30)$ & 0.19 & $(0.23)$ & $4.28 * * *$ & $(0.30)$ \\
\hline $14-15$ / 18 years old & $0.47 *$ & $(0.27)$ & $4.41 * * *$ & $(0.30)$ & $0.48^{*}$ & $(0.27)$ & $4.38 * * *$ & $(0.31)$ \\
\hline $16-19 / 19$ years old & 0.16 & $(0.30)$ & $3.28 * * *$ & $(0.41)$ & 0.17 & $(0.31)$ & $3.25 * * *$ & $(0.41)$ \\
\hline $20+/ 20-21$ years old & -0.53 & $(0.40)$ & $3.67 * * *$ & $(0.33)$ & -0.54 & $(0.41)$ & $3.63 * * *$ & $(0.34)$ \\
\hline$. / 22-23$ years old & & & $3.74 * * *$ & $(0.33)$ & & & $3.70 * * *$ & $(0.34)$ \\
\hline$. / 24-26$ years old & & & $3.53 * * *$ & $(0.35)$ & & & $3.48 * * *$ & $(0.35)$ \\
\hline$. / 27+$ years old & & & $4.11 * * *$ & $(0.34)$ & & & $4.04 * * *$ & $(0.34)$ \\
\hline Second masspoint & $-\infty$ & & $-\infty$ & & $-\infty$ & & $-\infty$ & \\
\hline$\alpha 2$ & $1.04 * * *$ & $(0.14)$ & $2.91 * * *$ & $(0.36)$ & & $8 * * *$ & $(0.15)$ & \\
\hline$\alpha 3$ & & & & & & $1 * * *$ & $(0.37)$ & \\
\hline$\alpha 4$ & & & & & - & & & \\
\hline Type 1 - high PS \& high H (\%) & 73.9 & & 94.8 & & 7 & & & \\
\hline Type 2 - low PS \& high H (\%) & & & & & & & & \\
\hline Type 3 - high PS \& low H (\%) & & & & & 3 & & & \\
\hline Type 4 - low PS \& low H (\%) & & & & & 0 & & & \\
\hline -Loglikelihood & $1,360.1$ & & $1,373.5$ & & & 3.5 & & \\
\hline
\end{tabular}

Notes: The age dependence structure for parental separation includes eight age intervals (indicated first) and the age dependence structure for homelessness includes 11 intervals (indicated last). Based on 564 observations; standard errors in parentheses; $* * * / * * / *$ indicates significance at a $1 / 5 / 10 \%$-level. 
Table 6: Parameter estimates mixed proportional hazards model, parental separation and homelessness, men

\begin{tabular}{|c|c|c|c|c|c|c|c|c|}
\hline \multirow{3}{*}{ Separation before age 12} & \multicolumn{4}{|c|}{ Separate } & \multicolumn{4}{|c|}{ Joint } \\
\hline & \multicolumn{2}{|c|}{$\begin{array}{c}\text { Parental } \\
\text { separation }\end{array}$} & \multicolumn{2}{|c|}{ Homelessness } & \multicolumn{2}{|c|}{$\begin{array}{c}\text { Parental } \\
\text { separation }\end{array}$} & \multicolumn{2}{|c|}{ Homelessness } \\
\hline & & & $1.02 * * *$ & $(0.15)$ & & & $0.70 * * *$ & $(0.18)$ \\
\hline Separation from age 12 to 30 & & & $0.87 * * *$ & $(0.19)$ & & & $0.83^{* * *}$ & $(0.22)$ \\
\hline \multicolumn{9}{|l|}{ Childhood } \\
\hline Parents dead & & & $0.61 * *$ & $(0.24)$ & & & $0.56 * *$ & $(0.26)$ \\
\hline Conflict parents & & & $1.16^{* * *}$ & $(0.25)$ & & & $1.08 * * *$ & $(0.24)$ \\
\hline Emotional abuse & $1.08 * * *$ & $(0.25)$ & $0.51 * * *$ & $(0.18)$ & $1.11 * * *$ & $(0.26)$ & $0.71 * * *$ & $(0.20)$ \\
\hline Physical violence & -0.02 & $(0.25)$ & $0.35^{*}$ & $(0.19)$ & -0.03 & $(0.26)$ & $0.36^{*}$ & $(0.20)$ \\
\hline Sexual violence & -0.14 & $(0.24)$ & 0.13 & $(0.17)$ & -0.10 & $(0.24)$ & 0.23 & $(0.19)$ \\
\hline \multicolumn{9}{|l|}{ Missing info } \\
\hline Reason not living with parents & & & 0.22 & $(0.45)$ & & & 0.12 & $(0.46)$ \\
\hline Violence & $0.49^{*}$ & $(0.27)$ & 0.23 & $(0.22)$ & 0.45 & $(0.27)$ & 0.26 & $(0.24)$ \\
\hline \multicolumn{9}{|l|}{ Male caregiver's education } \\
\hline Primary school & -0.63 & $(0.84)$ & $-1.03 *$ & $(0.56)$ & -0.58 & $(0.93)$ & $-1.39 * *$ & $(0.68)$ \\
\hline Some secondary, $<=\mathrm{Y} 10$ & -0.36 & $(0.78)$ & -0.36 & $(0.54)$ & -0.26 & $(0.82)$ & -0.52 & $(0.65)$ \\
\hline Y11 or equivalent & 0.07 & $(0.94)$ & -0.49 & $(0.70)$ & 0.01 & $(0.96)$ & -0.79 & $(0.80)$ \\
\hline Y12 or equivalent & -0.15 & $(0.81)$ & -0.10 & $(0.56)$ & -0.14 & $(0.86)$ & -0.42 & $(0.67)$ \\
\hline Technical College/TAFE & -0.98 & $(0.83)$ & -0.83 & $(0.58)$ & -0.87 & $(0.88)$ & $-1.16^{*}$ & $(0.69)$ \\
\hline University & -0.74 & $(0.81)$ & -0.69 & $(0.58)$ & -0.65 & $(0.86)$ & -1.02 & $(0.70)$ \\
\hline Missing & 0.32 & $(0.77)$ & -0.18 & $(0.53)$ & 0.37 & $(0.81)$ & -0.33 & $(0.63)$ \\
\hline \multicolumn{9}{|l|}{ Female caregiver's education } \\
\hline Primary school & 0.51 & $(0.64)$ & -0.29 & $(0.50)$ & 0.46 & $(0.68)$ & -0.30 & $(0.54)$ \\
\hline Some secondary, $<=\mathrm{Y} 10$ & $1.35 * *$ & $(0.57)$ & $0.74 *$ & $(0.44)$ & $1.19 * *$ & $(0.60)$ & $0.97 * *$ & $(0.47)$ \\
\hline Y11 or equivalent & $1.44 * *$ & $(0.72)$ & 0.67 & $(0.51)$ & $1.42 *$ & $(0.75)$ & 0.90 & $(0.56)$ \\
\hline Y12 or equivalent & 0.94 & $(0.60)$ & 0.37 & $(0.45)$ & 0.90 & $(0.62)$ & 0.65 & $(0.48)$ \\
\hline Technical College/TAFE & 1.05 & $(0.67)$ & 0.26 & $(0.52)$ & 0.90 & $(0.70)$ & 0.50 & $(0.56)$ \\
\hline University & 0.57 & $(0.63)$ & 0.53 & $(0.50)$ & 0.41 & $(0.65)$ & 0.62 & $(0.52)$ \\
\hline Missing & 0.66 & $(0.56)$ & 0.53 & $(0.43)$ & 0.63 & $(0.59)$ & $0.89^{*}$ & $(0.46)$ \\
\hline Constant & $-3.65 * * *$ & $(0.77)$ & $-6.80 * * *$ & $(0.60)$ & $-3.55 * * *$ & $(0.83)$ & $-6.83 * * *$ & $(0.68)$ \\
\hline \multicolumn{9}{|l|}{ Age (separation / homelessness) } \\
\hline $4-5 / 12-13$ years old & -0.07 & $(0.19)$ & $1.53 * * *$ & $(0.29)$ & -0.06 & $(0.20)$ & $1.59 * * *$ & $(0.30)$ \\
\hline $6-7 / 14$ years old & 0.17 & $(0.20)$ & $2.78 * * *$ & $(0.25)$ & 0.21 & $(0.22)$ & $2.85 * * *$ & $(0.26)$ \\
\hline $8-9$ / 15 years old & 0.19 & $(0.24)$ & $3.35 * * *$ & $(0.24)$ & 0.24 & $(0.26)$ & $3.43 * * *$ & $(0.25)$ \\
\hline $10-11 / 16$ years old & 0.36 & $(0.27)$ & $3.79 * * *$ & $(0.24)$ & 0.40 & $(0.29)$ & $3.90 * * *$ & $(0.25)$ \\
\hline $12-13 / 17$ years old & $0.67 * *$ & $(0.28)$ & $4.13^{* * *}$ & $(0.24)$ & $0.71 * *$ & $(0.30)$ & $4.30 * * *$ & $(0.25)$ \\
\hline $14-15$ / 18 years old & $0.60 *$ & $(0.33)$ & $4.05 * * *$ & $(0.27)$ & $0.62 *$ & $(0.36)$ & $4.28 * * *$ & $(0.28)$ \\
\hline $16-19 / 19$ years old & 0.28 & $(0.34)$ & $3.96^{* * *}$ & $(0.29)$ & 0.28 & $(0.36)$ & $4.27 * * *$ & $(0.30)$ \\
\hline $20+/ 20-21$ years old & -0.40 & $(0.38)$ & $3.41 * * *$ & $(0.31)$ & -0.40 & $(0.40)$ & $3.79 * * *$ & $(0.33)$ \\
\hline$. / 22-23$ years old & & & $3.38 * * *$ & $(0.33)$ & & & $3.86^{* * *}$ & $(0.34)$ \\
\hline$. / 24-26$ years old & & & $3.39 * * *$ & $(0.33)$ & & & $3.95 * * *$ & $(0.36)$ \\
\hline$. / 27+$ years old & & & $3.82 * * *$ & $(0.33)$ & & & $4.46^{* * *}$ & $(0.37)$ \\
\hline Second masspoint & $-2.72 * * *$ & $(0.32)$ & $-2.37 * * *$ & $(0.36)$ & $-2.62 * * *$ & $(0.33)$ & $-2.76 * * *$ & $(0.32)$ \\
\hline$\alpha 1$ & -0.02 & $(0.20)$ & $1.28 * * *$ & $(0.30)$ & & $3 * *$ & $(0.21)$ & \\
\hline$\alpha 2$ & & & & & 0.3 & & $(0.25)$ & \\
\hline$\alpha 3$ & & & & & & $7 * * *$ & $(0.46)$ & \\
\hline Type 1 - high PS \& high H (\%) & 49.6 & & 78.2 & & 38 & & & \\
\hline Type 2 - low PS \& high H (\%) & & & & & 32 & & & \\
\hline Type 3 - high PS \& low H (\%) & & & & & 6.4 & & & \\
\hline Type 4 - low PS \& low H (\%) & & & & & 22 & & & \\
\hline -Loglikelihood & $1,550.0$ & & $1,629.9$ & & 3,1 & 74.7 & & \\
\hline
\end{tabular}


Table 7: Parameter estimates OLS and mixed proportional hazards model, type of homelessness

\begin{tabular}{|c|c|c|c|c|}
\hline & $\begin{array}{r}\text { Women (S } \\
\text { Homelessness }\end{array}$ & $\begin{array}{c}\text { ate } \mathrm{H} \text { model) } \\
\text { Literal } \\
\text { homelessness }\end{array}$ & $\begin{array}{r}\text { Men (. } \\
\text { Homelessness }\end{array}$ & $\begin{array}{l}\text { It model) } \\
\text { Literal } \\
\text { homelessness }\end{array}$ \\
\hline \multicolumn{5}{|c|}{$\begin{array}{l}\text { a. Linear probability model - The effect of parental separation before age } \overline{12} \\
\text { On literal homelessness }\end{array}$} \\
\hline$<=15$ & $\begin{array}{c}0.13^{* * *} \\
(0.04)\end{array}$ & $\begin{array}{c}0.11 * * * \\
(0.04)\end{array}$ & $\begin{array}{c}0.11 * * * \\
(0.03)\end{array}$ & $\begin{array}{c}0.07 * * \\
(0.03)\end{array}$ \\
\hline $\begin{array}{l}\text { On literal homelessness } \\
<=20\end{array}$ & $\begin{array}{c}0.25^{* * *} \\
(0.04)\end{array}$ & $\begin{array}{c}0.27 * * * \\
(0.05)\end{array}$ & $\begin{array}{c}0.25^{* * *} \\
(0.04)\end{array}$ & $\begin{array}{c}0.18^{* * *} \\
(0.04)\end{array}$ \\
\hline $\begin{array}{l}\text { On literal homelessness } \\
<=25\end{array}$ & $\begin{array}{c}0.24 * * * \\
(0.04)\end{array}$ & $\begin{array}{c}0.32 * * * \\
(0.05)\end{array}$ & $\begin{array}{c}0.26 * * * \\
(0.04)\end{array}$ & $\begin{array}{c}0.25 * * * \\
(0.04)\end{array}$ \\
\hline $\begin{array}{l}\text { On literal homelessness } \\
<=30\end{array}$ & $\begin{array}{c}0.22 * * * \\
(0.03)\end{array}$ & $\begin{array}{c}0.30 * * * \\
(0.05)\end{array}$ & $\begin{array}{c}0.23 * * * \\
(0.03)\end{array}$ & $\begin{array}{c}0.26 * * * \\
(0.04)\end{array}$ \\
\hline b. Mixed proportional hazards $\mathrm{r}$ & odel - The effec & literal homele & & \\
\hline Of separation before 12 & $\begin{array}{l}0.80^{* * *} \\
(0.1)\end{array}$ & $\begin{array}{c}0.90^{* * * *} \\
(0.2)\end{array}$ & $\begin{array}{l}0.70^{* * *} \\
(0.2)\end{array}$ & $\begin{array}{c}0.72 * * * \\
(0.2)\end{array}$ \\
\hline Of separation from 12 to 30 & $\begin{array}{l}0.07 \\
(0.2)\end{array}$ & $\begin{array}{l}-0.05 \\
(0.3)\end{array}$ & $\begin{array}{c}0.83 * * * \\
(0.2)\end{array}$ & $\begin{array}{c}0.66^{* *} \\
(0.3)\end{array}$ \\
\hline
\end{tabular}

\section{Notes:}

In section a (linear probability models), we remove from the sample homeless spells occurring before age 12 . In section $\mathrm{b}$ (mixed proportional hazards models), the age dependence structure for parental separation includes eight age intervals and the age dependence structure for homelessness includes 11 intervals (as in Tables 6 and 7).

The estimates from the 'Homelessness' columns are taken from tables 3-6. Literal homelessness is defined as having stayed in crisis accommodation, squatted in abandoned buildings or slept rough.

Based on 564 women and 667 men; robust standard errors in parentheses; ***/**/* indicates significance at a 1/5/10\%-level. 
Table 8: Sensitivity analysis

\begin{tabular}{|c|c|c|c|c|c|c|}
\hline & \multicolumn{3}{|c|}{ Women (Separate H model) } & \multicolumn{3}{|c|}{ Men (Joint model) } \\
\hline & Coeff. & s.e. & -Loglik. & Coeff. & s.e. & -Loglik. \\
\hline 1. With 1 treatment effect before 30 & $0.64 * * *$ & $(0.13)$ & $1,380.81$ & $0.73 * * *$ & $(0.16)$ & $3,174.88$ \\
\hline \multicolumn{7}{|l|}{ 2. With 3 treatment effects } \\
\hline Separation before 12 & $0.80 * * *$ & $(0.13)$ & $1,373.51$ & $0.72 * * *$ & $(0.17)$ & $3,174.19$ \\
\hline Separation from 12 to 16 & 0.08 & $(0.22)$ & & $0.99 * * *$ & $(0.23)$ & \\
\hline Separation from 17 to 30 & 0.04 & $(0.45)$ & & 0.51 & $(0.49)$ & \\
\hline 3. With 1 treatment effect before 12 & $0.79 * * *$ & $(0.12)$ & $1,373.58$ & $0.58 * * *$ & $(0.16)$ & $3,179.75$ \\
\hline 4. Censoring after 25 & $0.85 * * *$ & $(0.13)$ & $1,221.46$ & $0.76^{* * *}$ & $(0.16)$ & $2,950.57$ \\
\hline 5. Censoring after 35 & $0.80 * * *$ & $(0.12)$ & $1,482.91$ & $0.77 * * *$ & $(0.16)$ & $3,348.11$ \\
\hline 6. Misreporting - over 3 years & $0.76^{* * *}$ & $(0.13)$ & 927.08 & $0.70 * * *$ & $(0.16)$ & $2,252.49$ \\
\hline 7. Marriages & $0.82 * * *$ & $(0.15)$ & 998.07 & $0.80 * * *$ & $(0.20)$ & $2,474.56$ \\
\hline 8. De facto relationships & 0.47 & $(0.32)$ & 353.27 & 0.37 & $(0.45)$ & 629.58 \\
\hline $\begin{array}{l}\text { 9. Without control for not living } \\
\text { with parents' because dead }\end{array}$ & $0.78 * * *$ & $(0.13)$ & $1,375.78$ & $0.69 * * *$ & $(0.16)$ & $3,177.82$ \\
\hline $\begin{array}{l}\text { 10. Without control for not living } \\
\text { with parents because of conflict }\end{array}$ & $0.85 * * *$ & $(0.12)$ & $1,392.41$ & $0.75 * * *$ & $(0.18)$ & $3,183.85$ \\
\hline 11. Without emotional abuse & $0.82 * * *$ & $(0.13)$ & $1,380.46$ & $0.81 * * *$ & $(0.16)$ & $3,191.19$ \\
\hline $\begin{array}{l}\text { 12. With control for utilities } \\
\text { disconnected }\end{array}$ & $0.74 * * *$ & $(0.13)$ & $1,371.03$ & $0.83 * * *$ & $(0.16)$ & $3,168.14$ \\
\hline 13. With control for State care & $0.73 * * *$ & $(0.12)$ & $1,370.28$ & $0.70 * * *$ & $(0.15)$ & $3,159.32$ \\
\hline $\begin{array}{l}\text { 14. With control for female } \\
\text { caregiver's substance abuse }\end{array}$ & $0.79 * * *$ & $(0.13)$ & $1,373.43$ & $0.89 * * *$ & $(0.17)$ & $3,168.83$ \\
\hline $\begin{array}{l}\text { 15. With control for female } \\
\text { caregiver's mental health issues }\end{array}$ & $0.77 * * *$ & $(0.13)$ & $1,371.27$ & $0.80 * * *$ & $(0.16)$ & $3,172.13$ \\
\hline $\begin{array}{l}\text { 16. With control for female } \\
\text { caregiver's incarceration }\end{array}$ & $0.79 * * *$ & $(0.13)$ & $1,373.43$ & $0.81 * * *$ & $(0.16)$ & $3,176.44$ \\
\hline $\begin{array}{l}\text { 17. With control for female } \\
\text { caregiver's long-term } \\
\text { unemployment }\end{array}$ & $0.77 * * *$ & $(0.13)$ & $1,372.21$ & $0.79 * * *$ & $(0.16)$ & $3,173.50$ \\
\hline $\begin{array}{l}\text { 18. With control for female } \\
\text { caregiver's gambling issues }\end{array}$ & $0.79 * * *$ & $(0.13)$ & $1,373.38$ & $0.81 * * *$ & $(0.16)$ & $3,175.11$ \\
\hline $\begin{array}{l}\text { 19. With control for male } \\
\text { caregiver's substance abuse }\end{array}$ & $0.77 * * *$ & $(0.13)$ & $1,370.03$ & $0.84 * * *$ & $(0.16)$ & $3,172.03$ \\
\hline $\begin{array}{l}\text { 20. With control for male } \\
\text { caregiver's mental health issues }\end{array}$ & $0.77 * * *$ & $(0.13)$ & $1,370.05$ & $0.84 * * *$ & $(0.16)$ & $3,173.06$ \\
\hline $\begin{array}{l}\text { 21. With control for male } \\
\text { caregiver's incarceration }\end{array}$ & $0.77 * * *$ & $(0.13)$ & $1,370.11$ & $0.80 * * *$ & $(0.16)$ & $3,171.76$ \\
\hline $\begin{array}{l}\text { 22. With control for male } \\
\text { caregiver's long-term } \\
\text { unemployment }\end{array}$ & $0.76^{* * *}$ & $(0.12)$ & $1,369.43$ & $0.83 * * *$ & $(0.16)$ & $3,170.57$ \\
\hline $\begin{array}{l}\text { 23. With control for male } \\
\text { caregiver's gambling issues }\end{array}$ & $0.77 * * *$ & $(0.13)$ & $1,370.22$ & $0.84 * * *$ & $(0.16)$ & $3,173.14$ \\
\hline
\end{tabular}

Notes: For panels 4 onwards, the effects estimated are for separations before age 12 for women, and before age 30 for men; standard errors in parentheses; $* * * / * * / *$ indicates significance at a $1 / 5 / 10 \%$-level. 
Figure 1: Cumulative starting probabilities for parental separation and the onset of homelessness, women
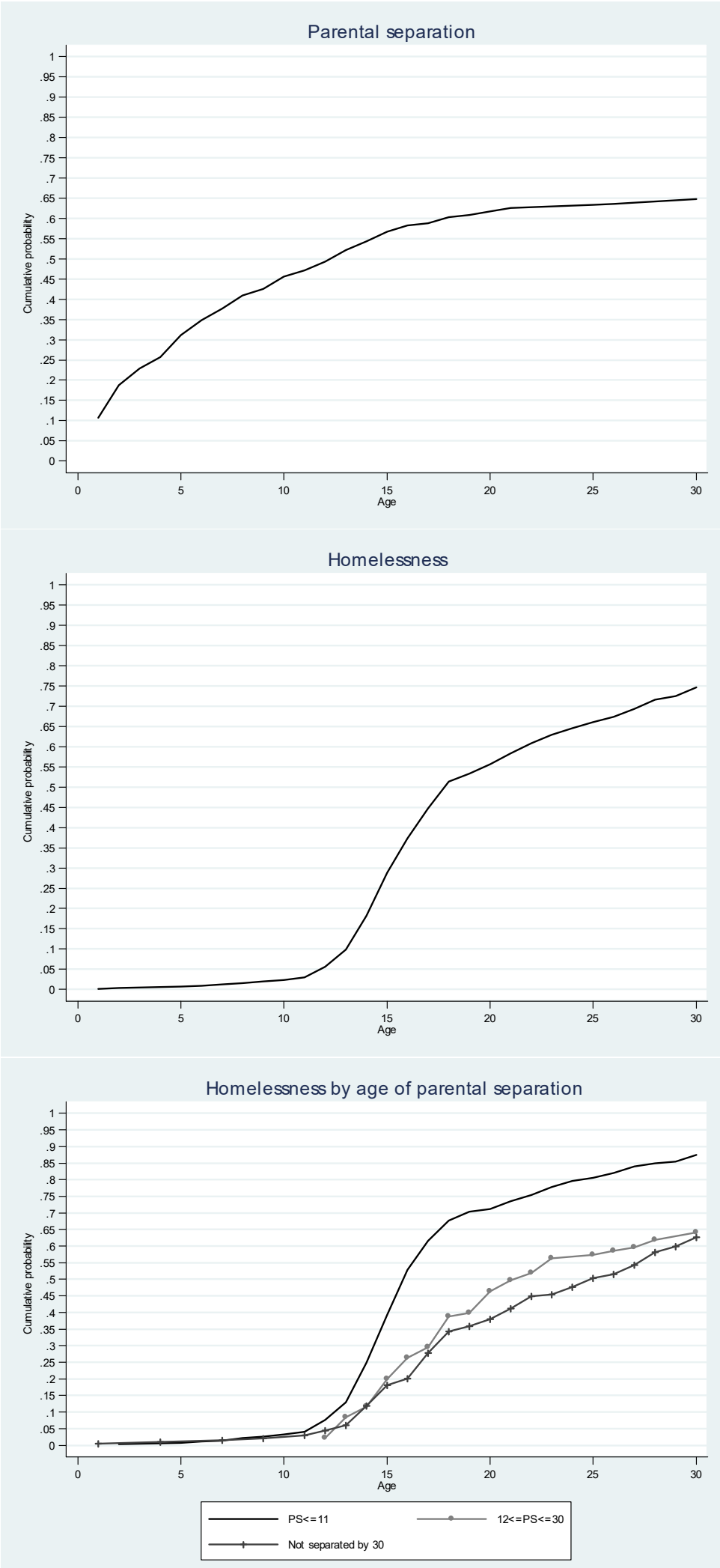
Figure 2: Cumulative starting probabilities for parental separation and the onset of homelessness, men
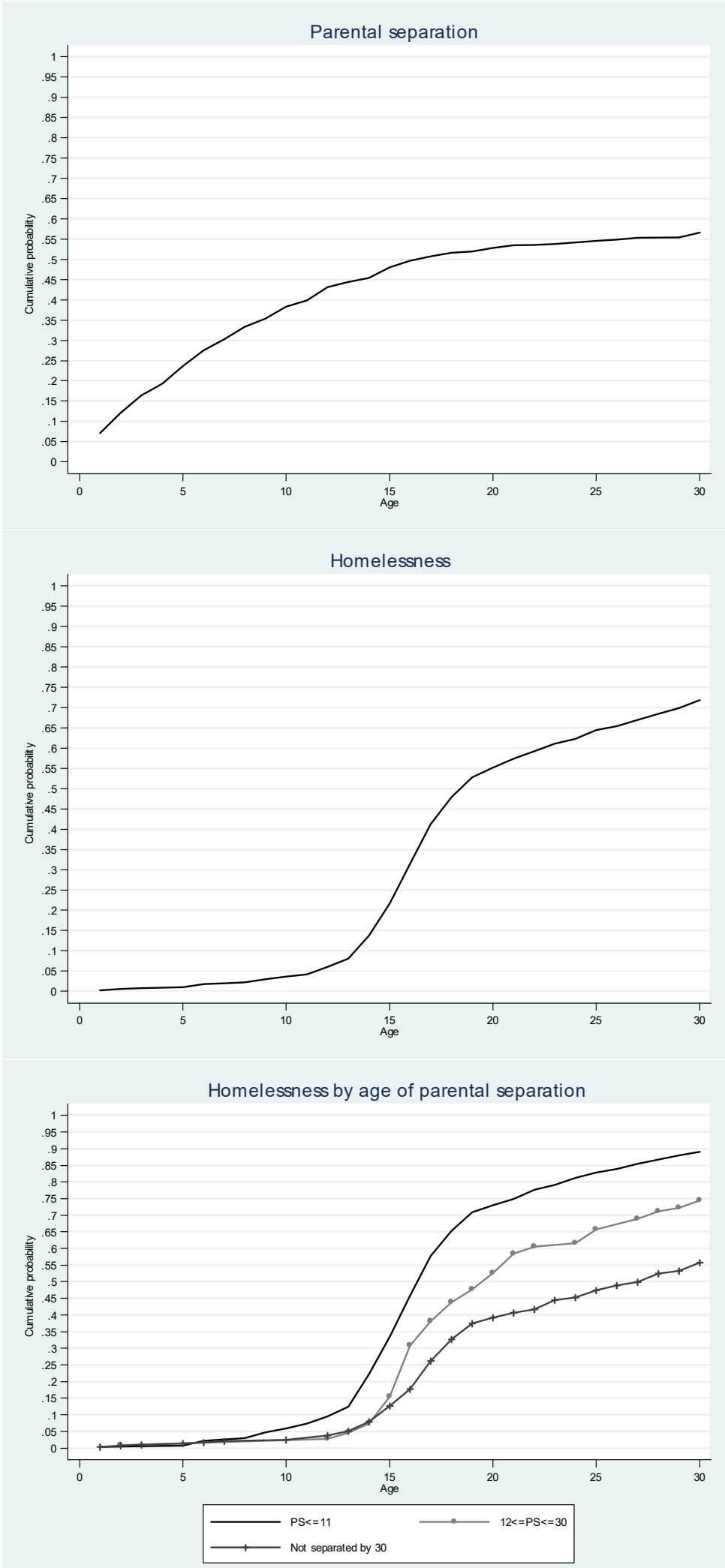
Figure 3: Association between the timing of parental separation and homelessness
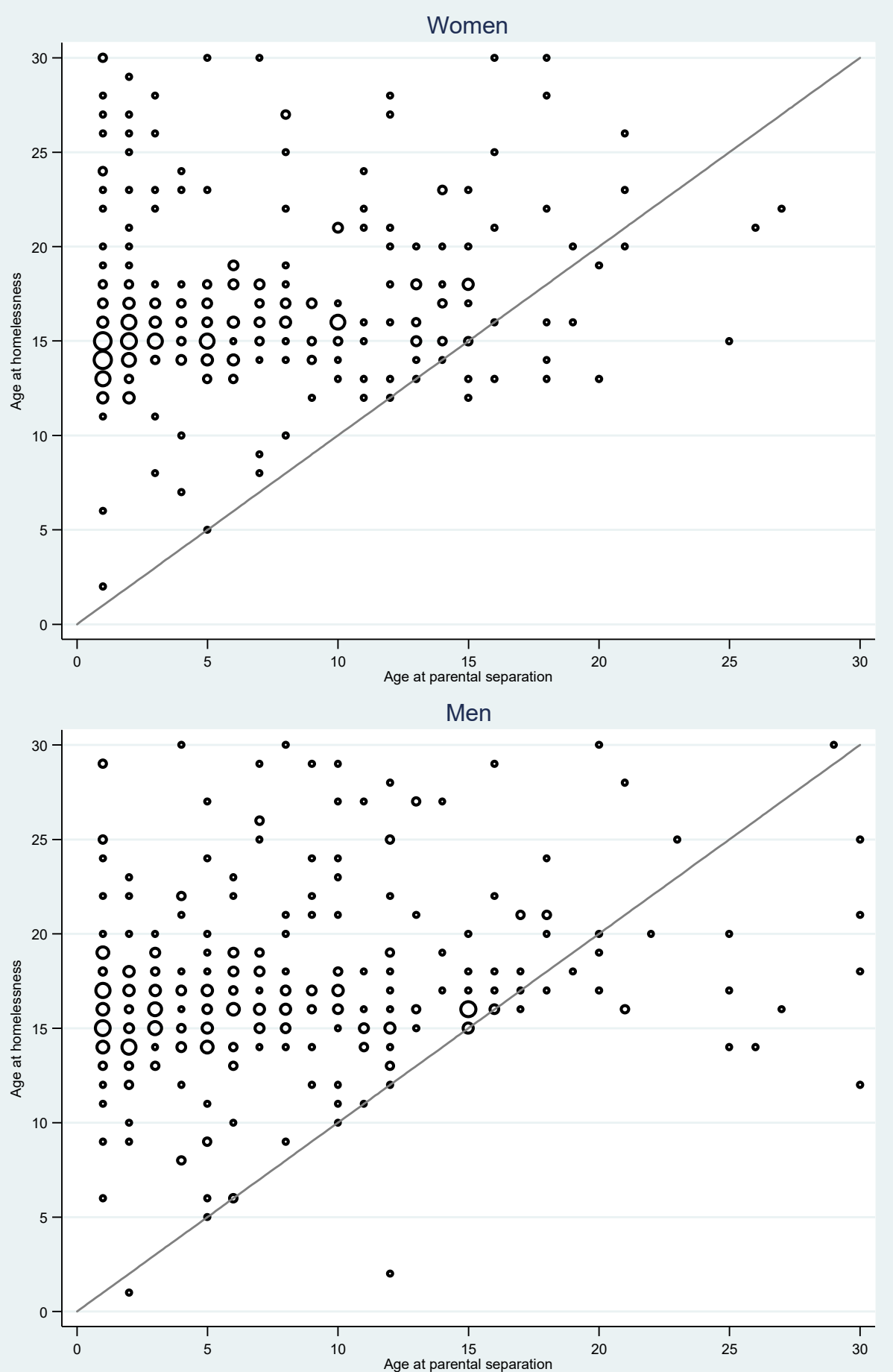

Notes: Wave 1 and 6 respondents with information on parental separation and homelessness $(1,231$

observations). Only homeless spells and parental separations occurring before 30 are considered. For women, in $47.7 \%$ of cases homelessness and/or parental separation is censored as it does not occur before 30 years old ( $12.4 \%$ with censored homelessness, $21.6 \%$ with censored separation, $13.7 \%$ with bot censored). Respectively for men: $9.3 \%, 24.3 \%$ and $19 \%$ of cases are censored. 
Figure 4: Simulated cumulative starting probabilities for the onset of homelessness, women
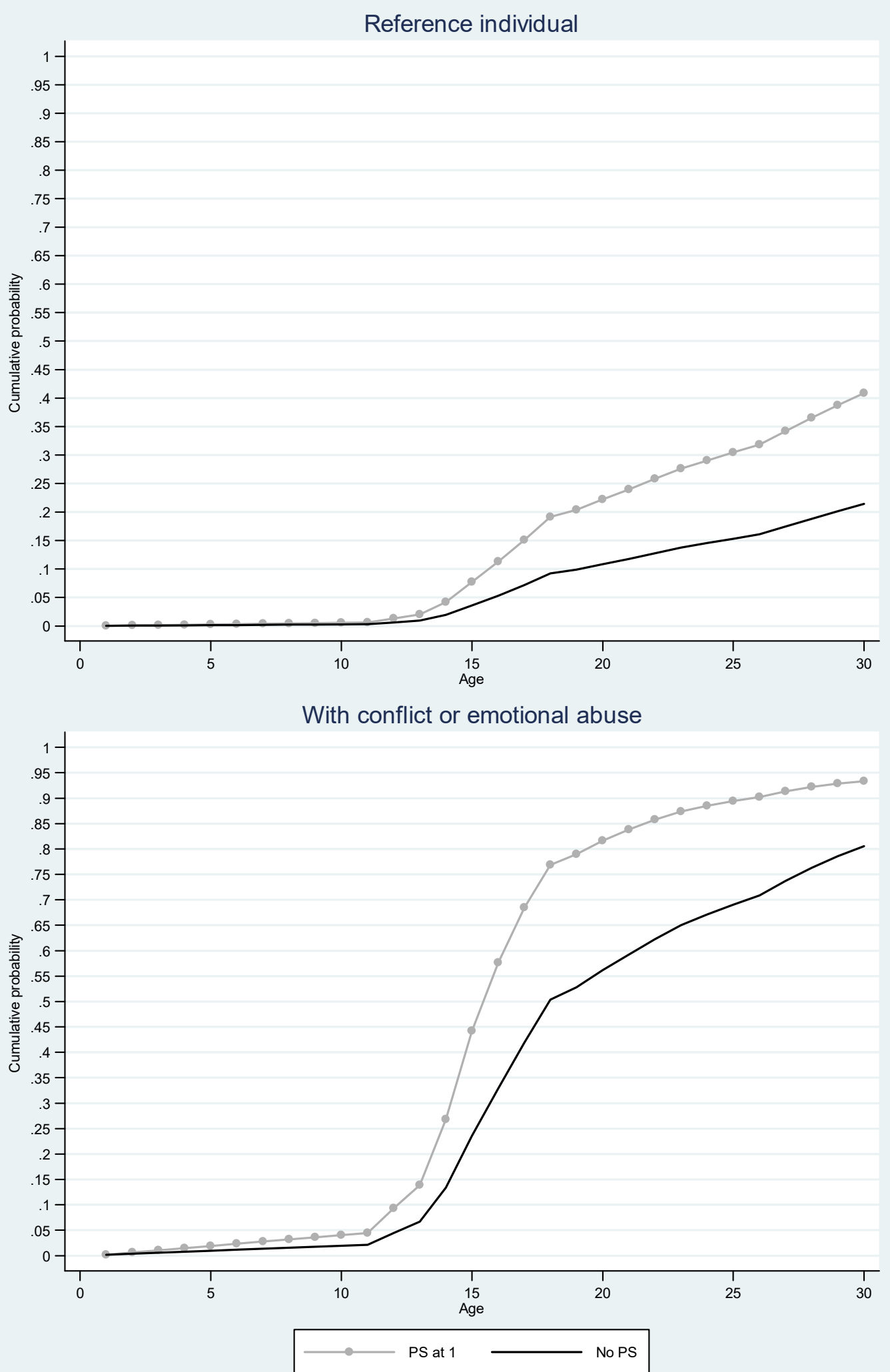
Figure 5: Simulated cumulative starting probabilities for the onset of homelessness, men
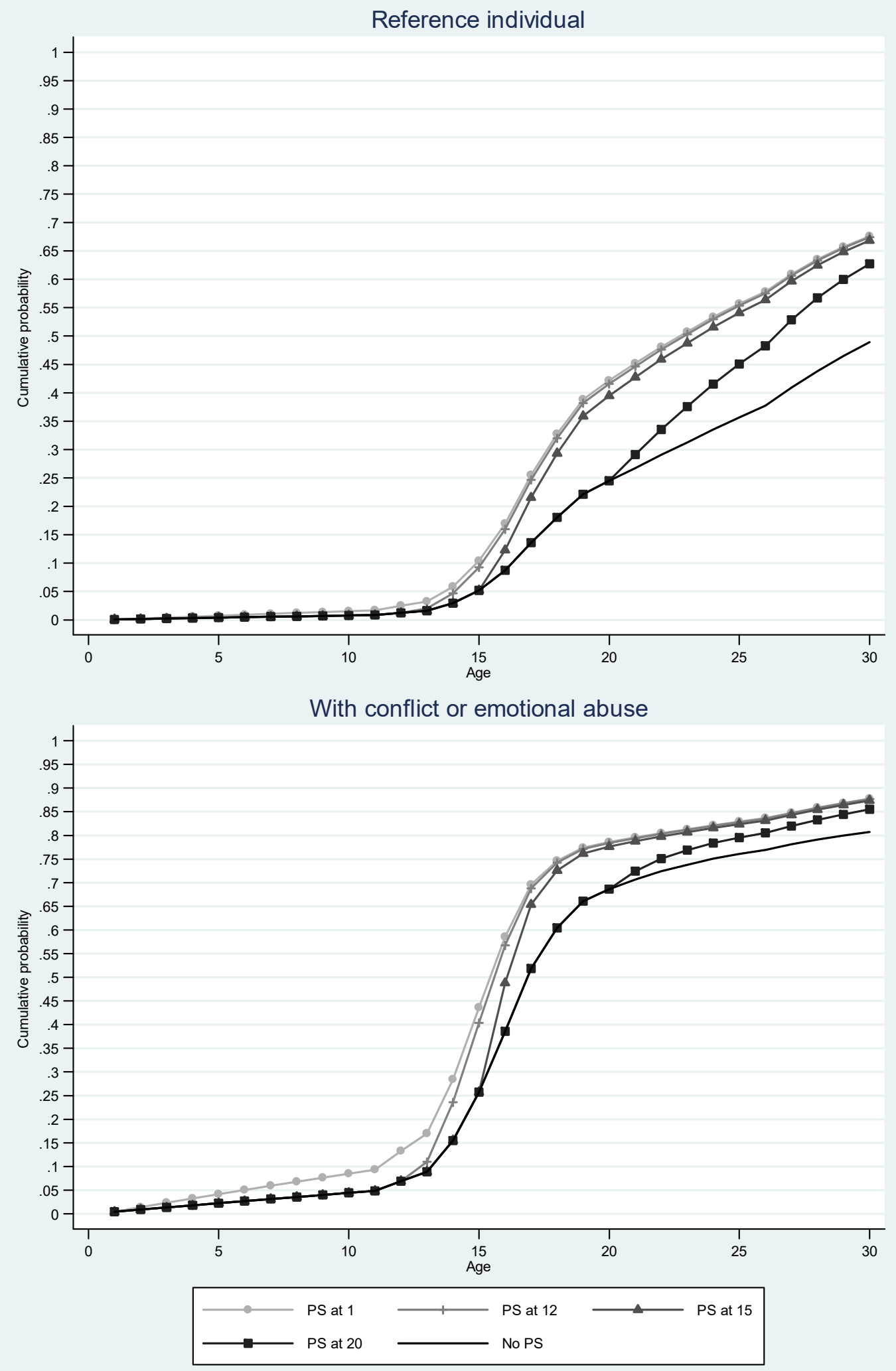
APPENDIX 1 - Selection on the outcome: the potential for upward vs downward bias

The JH sample is a subset of the population, selected because they are disadvantaged and display high occurrences of homelessness. While this selection is useful to analyse homelessness, it may generate biases by modifying the structure of the sample in a way that is correlated with parental separation. Estimates produced on the $\mathrm{JH}$ sample are biased due to sample selection if the unobservables determining the selection into the $\mathrm{JH}$ sample are correlated with the unobservables determining homelessness in a way that relates to parental separation. In other words, the bias due to sample selection depends on: (i) how well the estimation model controls for the characteristics that determine selection into JH; (ii) whether parental separation correlates with unobservable selection characteristics and the sign of this correlation.

Our estimated model includes controls that characterise disadvantage which probably reduces biases due to the selection of the sample. The list of control variables included in our model covers: reasons for not living with one's parent's at age 14, emotional abuse, physical and sexual violence, male and female caregiver's education (see Table 2 for the complete list); and in Table 8: financial difficulties in childhood, placement in State Care and caregivers' problematic outcomes (substance use, incarceration, gambling, long-term unemployment and mental health). In addition, our bivariate duration framework controls for all time-invariant characteristics. Broadly speaking what determines selection into $\mathrm{JH}$ is: being flagged by Centrelink as homeless or at-risk of homelessness; or being assessed as statistically vulnerable to homelessness, i.e. be extremely disadvantaged. The modelling of vulnerability to homelessness included variables such as: key demographics, housing tenure type, residential mobility in the past year, earnings, income support history, medical conditions, incarceration history, substance use (see Table A1 in Melbourne Institute, 2012, for the full list). The controls in our model and in the modelling of vulnerability are far from being identical but cover similar aspects of disadvantage and are therefore probably correlated to some extent. Accounting for time invariant unobserved heterogeneity implies that the remaining bias would have to arise from time-varying unobservables that would have affected youth homelessness (the outcome) as well as selection into $\mathrm{JH}$ later on. The size and direction of the remaining bias is unclear.

In the absence of a perfect correction, we illustrate the circumstances under which a bias appears and discuss the possibility of an upward versus downward bias. Assume that the population consists of three subgroups with respect to their homelessness experience: individuals who have experienced homelessness; individuals who have not experienced homelessness but are at-risk; individuals who have not experienced homelessness and are not at-risk. The first two subgroups are disadvantaged and are represented in our sample while the third group is not. In each of those three subgroups, individuals may have separated parents or not resulting in 6 subgroups with column proportions $x_{1}$ to $x_{3}$ and $y_{1}$ to $y_{3}$ :

\begin{tabular}{lccl}
\hline & $\begin{array}{c}\text { Parental } \\
\text { separation }\end{array}$ & $\begin{array}{c}\text { No parental } \\
\text { separation }\end{array}$ & \\
\cline { 1 - 4 } Homeless & $x_{1}$ & $y_{1}$ & $\begin{array}{l}\text { Disadvantaged } \\
\text { individuals }\end{array}$ \\
\hline At risk of homelessness & $x_{2}$ & $y_{2}$ & Advantaged individuals \\
\hline Not at risk of homelessness & $x_{3}$ & $y_{3}$ & \\
\hline Total & 1 & 1 & \\
\hline
\end{tabular}

In a simple framework without controls (and assuming parental separation is exogenous), the effect of parental separation on homelessness can be expressed as an odds-ratio: 
- For the population: $\frac{x_{1}}{y_{1}}$

- For the JH sample: $\frac{x_{1}}{x_{1}+x_{2}} / \frac{y_{1}}{y_{1}+y_{2}}=\frac{x_{1}}{1-x_{3}} / \frac{y_{1}}{1-y_{3}}$

Estimates generated from the $\mathrm{JH}$ sample are downward biased if:

$$
\text { - } \quad \frac{x_{1}}{y_{1}}>\frac{x_{1}}{1-x_{3}} / \frac{y_{1}}{1-y_{3}} \rightarrow \frac{1}{1-x_{3}}<\frac{1}{1-y_{3}} \rightarrow x_{3}<y_{3}
$$

Similarly, estimates generated from the JH sample are upward biased if $x_{3}>y_{3}$ and unbiased if $x_{3}=y_{3}$. Intuitively, a bias arises if the proportion of advantaged individuals (not in $\mathrm{JH}$ ) differs by parental separation status. Specifically, if individuals with separated parents are less (resp. more) likely to be advantaged than individuals whose parents did not separate ( $x_{3}$ $<y_{3}$ ), a downward (resp. upward) bias arises. Theoretically, either of these biases is possible. For example, it is possible that advantaged families separate more often because they have less financial constraints. At the same time, it is possible that parental separation is relatively more common among disadvantaged families.

To get a sense of the direction of the bias, ideally one needs information on parental separation and disadvantage (i.e. the characteristics that differentiate individuals in and out of $\mathrm{JH})$. In the absence of information on the $\mathrm{JH}$ disadvantage status for a representative sample of Australian residents, we compare the educational attainment of individuals whose parents separated when they were a child with that of individuals whose parents did not separate. After all, low education is correlated with being disadvantaged and thus should be correlated with selection into the sample. Among individuals aged 18 to 24 with divorced/separated parents, only $60 \%$ complete year 12 versus $75 \%$ for those whose parents did not divorce/separate (Australian Bureau of Statistics, 2006-2007 Family Characteristics and Transitions Survey). For older individuals there is a similar difference. A similar picture is provided by the Australian household panel data (see Hilda Statistical Report 1 Table 3 p.14) showing negative relationships between not living with biological parents at 14 and respondents' education level, wages and wealth. This is consistent with the negative correlation between parental separation and children's education outcomes found in the economic and sociological literature (McLanahan et al., 2013). The fact that the share of advantaged individuals is consistently lower for individuals whose parents separated implies that $x_{3}<y_{3}$. Therefore, a downward bias in estimates using the JH sample is more likely than an upward bias. In other words, our estimate of parental separation having a positive effect on the transition into homelessness is likely to be a lower bound of the true effect (if our control variables only capture imperfectly the selection into $\mathrm{JH}$ ). 


\section{APPENDIX 2 - JH sample vs the Australian population}

Figure A1: Distribution of individual gross yearly income for $\mathrm{JH}$ respondents vs the Australian population (HILDA)

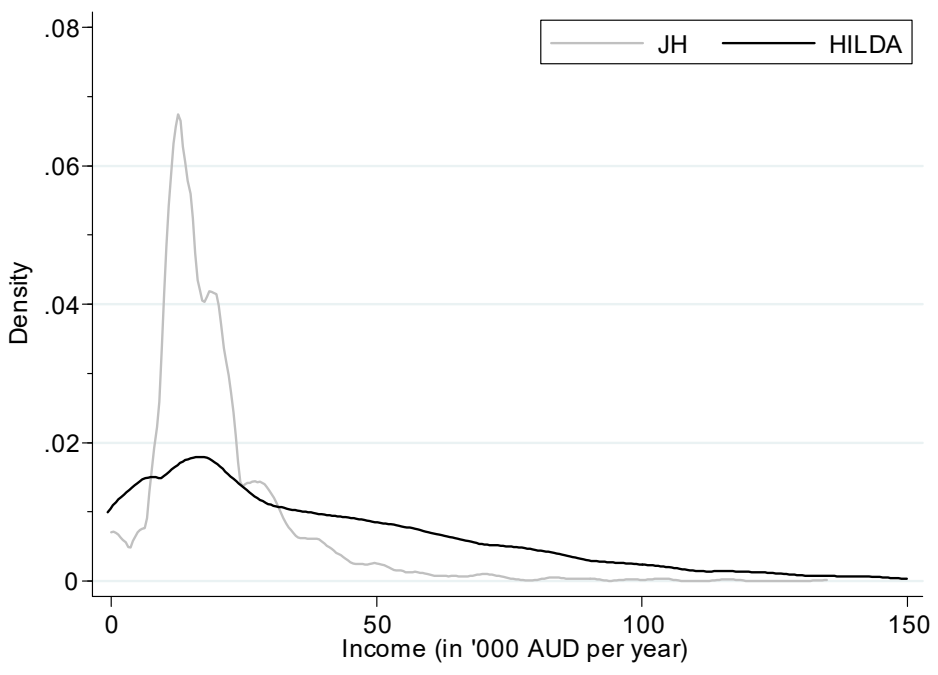

Note: The distribution for $\mathrm{JH}$ respondents is based on their declared weekly income in all jobs and other incomes, and the government payments they received (administrative source) in wave 1 (2011). The distribution for the Australian population is calculated from Hilda 2011 using the derived 'Financial year gross regular income' variable and cross-sectional population weights.

The two sources are not exactly similar. For instance, the collection of government payments is likely to be underestimated in Hilda as it is self-reported compared to the use of administrative data in JH. This may superficially increase the number of respondents with very low income in Hilda and explain that the black line is over the grey line on the left side of the distribution. 
APPENDIX 3 - Survey instruments on homelessness and parental separation

1. Questions identifying the age of onset of homelessness (wave 1)

\section{H26 [hhishmls]}

Thinking about both your current and past experiences, have you ever stayed in any of the following places because you did not have a place to live? Interviewer note: by a place to live we mean a place that the respondent either owned, was renting, or was buying. If necessary clarify: a "temporary stay" is one in which a person has stayed or intends to stay with relatives or friends for less than 3 months. Read out all categories.

\begin{tabular}{|c|c|c|c|c|c|}
\hline & Yes & No & $\begin{array}{l}\text { Don’t } \\
\text { know }\end{array}$ & Refused & \\
\hline $\begin{array}{l}\text { Stayed with relatives temporarily (because you } \\
\text { did not have a place to live) (1) }\end{array}$ & $\square$ & $\square$ & $\square$ & $\square$ & [hhhis1] \\
\hline $\begin{array}{l}\text { Stayed at a friend's house temporarily (because } \\
\text { you did not have a place to live) (2) }\end{array}$ & $\square$ & $\square$ & $\square$ & $\square$ & [hhhis2] \\
\hline $\begin{array}{l}\text { Stayed in a caravan, mobile home, cabin, } \\
\text { houseboat (because you did not have a place to } \\
\text { live) ( } 3 \text { ) }\end{array}$ & $\square$ & $\square$ & $\square$ & $\square$ & [hhhis3] \\
\hline $\begin{array}{l}\text { Stayed at a boarding house or hostel (because you } \\
\text { did not have a place to live) (4) }\end{array}$ & $\square$ & $\square$ & $\square$ & $\square$ & [hhhis4] \\
\hline $\begin{array}{l}\text { Stayed in a hotel or motel (because you did not } \\
\text { have a place to live) (5) }\end{array}$ & $\square$ & $\square$ & $\square$ & $\square$ & [hhhis5] \\
\hline Stayed in crisis accommodation or a refuge (6) & $\square$ & $\square$ & $\square$ & $\square$ & [hhhis6] \\
\hline Squatted in an abandoned building (7) & $\square$ & $\square$ & $\square$ & $\square$ & [hhhis7] \\
\hline $\begin{array}{l}\text { Slept rough (such as sleeping in cars, tents, trains } \\
\text { or anywhere else outdoors) (because you did not } \\
\text { have a place to live) (8) }\end{array}$ & $\square$ & $\square$ & $\square$ & $\square$ & [hhhis8] \\
\hline
\end{tabular}

\section{H28 [hfhlage]}

How old were you the first time that you were without a place to live?

[AGE]

$\square$ Don't know (-1)

$\square$ Refused (-2)

2. Questions identifying the age at parental separation (wave 6)

\section{PM1 [cgmarry]}

I am now going to ask a few questions about your parents. First, were your parents ever married to each other? Interviewer note: If queried, by "parents" we mean either their biological OR adoptive parents.

Yes (1)

No (0)

Don't know (-1)

Refused (-2) 


\section{PM2 [cgdfcto]}

Did they ever live together in a relationship?

$\square$ Yes (1)

$\square$ No $(0)$

$\square$ Don't know (-1)

$\square$ Refused (-2)

\section{PM3 [cgdvorc]}

Did your parents ever get divorced?

$\square$ Yes (1)

$\square$ No (0)

$\square$ Don't know (-1)

$\square$ Refused (-2)

\section{PM4 [cgseprte]}

Did your parents ever separate?

$\square$ Yes (1)

$\square$ No (0)

$\square$ Don't know (-1)

$\square$ Refused (-2)

\section{PM6 [cgfirst]}

About how old were you at the time they first separated?

$\square$ Unborn (0)

$\square$ Less than 1 year $(0)$

1 to 80 years (insert age)

Don't Know (-1)

$\square$ Refused (-2) 
ONLINE APPENDIX 4 (not for publication) - Sample selection on prior homelessness

Table A1: Regression estimates of the effect of homelessness prior to Journeys Home on the likelihood to be in our sample

\begin{tabular}{lcc}
\hline & Women & Men \\
\hline Homelessness before W1 & & \\
No controls & -0.03 & -0.02 \\
& $(0.04)$ & $(0.03)$ \\
All controls & -0.04 & -0.02 \\
& $(0.04)$ & $(0.04)$ \\
$\mathrm{N}$ & 763 & 917 \\
\hline
\end{tabular}

Notes:

The outcome is a dummy equal to 1 for the 1231 respondents in our sample and 0 for other wave 1 respondents. The controls included on the second row are identical to the ones included in tables 3 to 6 .

Standard errors in parentheses; $* * * * * / *$ indicates significance at a $1 / 5 / 10 \%$-level. 


\section{ONLINE APPENDIX 5 (not for publication) - Additional parameter estimates}

In our baseline estimates we find clear effects of parental separation on the transition rate to homelessness. In this appendix we explore whether this effect is related to time effects, such as the effect of the economic cycle and birth cohorts.

For example, parental separation and homelessness possibly increase concomitantly during recessions, possibly confounding our estimates. In our sample, we don't have enough parental separations per calendar year to add year dummies. Instead, we control for the unemployment rate in the year of parental separation. The unemployment rates in the period 1967-2012 are presented in Figure R1-2.

\section{Figure A2 Unemployment rates in Australia}

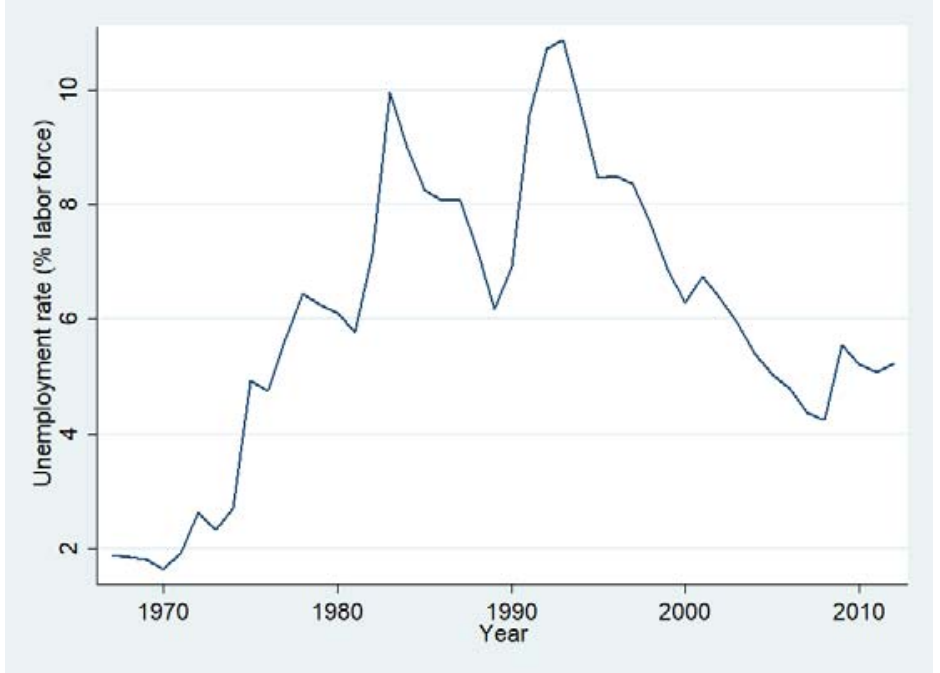

Source: OECD Labour Force Statistics

As shown, the unemployment rate varies from about $2 \%$ in the late 1970 s to more than $10 \%$ in the early 1990s. We link yearly unemployment rates to the calendar year of parental separation. For parental separation that occurred before 1967 ( 3 women and 2 men) we assume that the unemployment rate was equal to the unemployment rate in 1967 . Weighted by the number of observations of individuals who experienced parental separation, the average unemployment rate in the year of parental separation is $7.3 \%$ for women and $7.4 \%$ for men.

Estimates including the demeaned unemployment rate in our models are shown in Table A2 (baseline parameter estimates shown on the first row for comparison purposes). Estimates show that controlling for the unemployment rate doesn't change our baseline estimates of the effect of parental separation. Those estimates also show that the unemployment rate in the year of parental separation has a positive effect on the transition into homelessness with the magnitude of the effects being very similar for men and women.

However, one needs to be careful in interpreting this additional finding. The unemployment rate may be picking up other potential determinants of the effects of parental separation such as a different institutional environment for earlier cohorts. Panel 3 of the table shows the relevant parameter estimates if we introduce a dummy variable for birth cohorts from 1980 onwards in the transition rate to homelessness for women and in the transition rates to homelessness and parental separation for men. The birth year of 1980 is a natural inflection point given that in our sample, the average birth year is 1978.9 and the median birth year is 1981. Now the positive effect of the unemployment rate disappears. The dummy variables are positive suggesting that conditional on the other characteristics, recent birth cohorts are more 
likely to make a transition to homelessness. Introducing this dummy variable lowers the effect of parental separation on homelessness more for women than for men. Nevertheless, the effects of parental separation on the transition rate to homelessness are still positive and highly significant.

Table A2 Economic cycle and birth cohort effects

\begin{tabular}{|c|c|c|c|c|c|c|c|}
\hline & \multicolumn{3}{|l|}{ Women } & \multicolumn{3}{|l|}{ Men } \\
\hline & & Coeff. & s.e. & -Loglik. & Coeff. & s.e. & -Loglik. \\
\hline 1. & Baseline & $0.79 * * *$ & $(0.12)$ & $1,373.58$ & $0.73 * * *$ & $(0.16)$ & $3,174.88$ \\
\hline \multirow[t]{2}{*}{2.} & Parental separation & $0.77 * * *$ & $(0.12)$ & & $0.70 * * *$ & $(0.18)$ & \\
\hline & $\begin{array}{l}\text { Unemployment rate } \\
\text { (demeaned) }\end{array}$ & $0.17 * * *$ & $(0.03)$ & $1,364.23$ & $0.16^{* * *}$ & $(0.04)$ & $3,167.97$ \\
\hline \multirow[t]{3}{*}{3.} & Parental separation & $0.51 * * *$ & $(0.13)$ & & $0.69 * * *$ & $(0.12)$ & \\
\hline & $\begin{array}{l}\text { Unemployment rate } \\
\text { (demeaned) }\end{array}$ & 0.05 & $(0.04)$ & & 0.02 & $(0.03)$ & \\
\hline & Birth cohort 1980 onwards & $1.32 * * *$ & $(0.15)$ & $1,319.83$ & $1.19 * * *$ & $(0.14)$ & $3,094.41$ \\
\hline \multirow[t]{2}{*}{4.} & Parental separation & $0.50 * * *$ & $(0.12)$ & & $0.68 * * *$ & $(0.12)$ & \\
\hline & Birth cohort 1980 onwards & $1.39 * * *$ & $(0.14)$ & $1,320.82$ & $1.23 * * *$ & $(0.13)$ & $3,094.72$ \\
\hline \multirow[t]{3}{*}{5.} & Before $1980 *$ PS & $0.56^{* * *}$ & $(0.19)$ & & $0.88 * * *$ & $(0.16)$ & \\
\hline & From 1980 onwards * PS & $0.49 * * *$ & $(0.15)$ & & $0.54 * * *$ & $(0.17)$ & \\
\hline & Birth cohort 1980 onwards & $1.42 * * *$ & $(0.19)$ & $1,320.77$ & $1.39 * * *$ & $(0.18)$ & 3093.41 \\
\hline
\end{tabular}

Note: dummy 1980 onward is in the transition rate to homelessness; for men there is a similar dummy in the transition to the parental separation rate (not reported)

Panel 4 of Table A2 shows the parameter estimates if we remove unemployment but still include the dummy variable representing a birth cohort effect in the transition to homelessness. These estimates are very similar to those in panel 3 . Although with the birth cohort effect our baseline estimate is smaller for women, it remains very significant, and estimates for men are unchanged (see estimates 3). At the same time, as shown in panel 5 of Table A2, the effect of parental separation is not very different for the two birth year periods. Indeed, as shown in the third part of the table we cannot reject that the effects are not dependent on birth year (the loglikelihoods are very similar). Note still that for men the effect of parental separation for the earlier birth cohorts is somewhat bigger than in the baseline estimates while the effect of the later birth cohorts is somewhat smaller than in the baseline estimate. 